\title{
Axonal degeneration as a therapeutic target in the CNS
}

\author{
Paul Lingor • Jan C. Koch • Lars Tönges • Mathias Bähr
}

Received: 30 November 2011 / Accepted: 2 February 2012/Published online: 6 March 2012

(C) The Author(s) 2012. This article is published with open access at Springerlink.com

\begin{abstract}
Degeneration of the axon is an important step in the pathomechanism of traumatic, inflammatory and degenerative neurological diseases. Increasing evidence suggests that axonal degeneration occurs early in the course of these diseases and therefore represents a promising target for future therapeutic strategies. We review the evidence for axonal destruction from pathological findings and animal models with particular emphasis on neurodegenerative and neurotraumatic disorders. We discuss the basic morphological and temporal modalities of axonal degeneration (acute, chronic and focal axonal degeneration and Wallerian degeneration). Based on the mechanistic concepts, we then delineate in detail the major molecular mechanisms that underlie the degenerative cascade, such as calcium influx, axonal transport, protein aggregation and autophagy. We finally concentrate on putative therapeutic targets based on the mechanistic prerequisites.
\end{abstract}

Keywords Neurodegeneration · Neurotrauma $\cdot$ Wallerian degeneration $\cdot$ Calcium $\cdot$ Autophagy

\section{Introduction}

The axon represents the largest functional entity in many neuronal populations, e.g. spanning up to more than one

Paul Lingor and Jan C. Koch contributed equally to this work.

P. Lingor $(\bowtie) \cdot$ J. C. Koch $\cdot$ L. Tönges $\cdot$ M. Bähr

Department of Neurology, University Medicine Göttingen,

Robert-Koch-Strasse 40,

37075 Göttingen, Germany

e-mail: plingor@gwdg.de meter in human motoneurons. Whereas the dysfunction of the cell soma and its consecutive degeneration in the course of neurological disorders dominated the perception in neuropathology for many years, an increasing amount of data supports the concept of axonal degeneration as the initial pathological mechanism. Thus, it comes to no surprise that many approaches aiming at neuroprotection and mainly somatic mechanisms (not specifically targeting the axon) have failed in functional long-term trials and in humans. The consideration of axonal degeneration as a major mechanistic step is therefore mandatory for the design of successful therapeutic strategies in disorders of the central nervous system (CNS).

The discovery of mutant mice that show a delay in Wallerian degeneration after injury through expression of the WldS (slow Wallerian degeneration) mutant protein (Lunn et al. 1989) prompted the idea that axonal degeneration, similar to apoptosis, is a controlled mechanism that does not occur in a random fashion but can be regulated. In similarity to programmed cell death, conserved mechanisms seem to participate in the course of traumatic and degenerative axonal demise. An understanding of these molecular pathways should therefore not only enable us to interact and interfere with degeneration in a true neuroprotective approach, but also could lay grounds for regenerative attempts.

This review starts with an overview of the evidence for axonal degeneration in pathological conditions and then addresses the morphological and molecular processes of axonal destruction. Finally, we summarize putative therapeutic strategies based on the current knowledge of molecular mechanisms. Because of the wealth of data and the rapid growth of information on the topic, we have had to make a selection of cited works reflecting our effort to draw 
a global picture rather than to provide an encyclopaedic compilation. We therefore apologize to all colleagues whose work could not be included.

\section{Axonal degeneration in CNS disease}

Traumatic injury to the brain or to the spinal cord most obviously involves primary axonal disruption. However, inflammatory disorders, such as multiple sclerosis (MS), and degenerative diseases, such as Alzheimer's disease (AD) and Parkinson's disease (PD), also show pronounced axonal pathology. We have to bear in mind that, although some parts of the degenerative cascade might indeed be similar in different pathologies, their origins may vary fundamentally. Membrane disruption in traumatic brain or spinal cord injury, for example, might eventually result in calcium influx, calpain-mediated cleavage and axonal transport breakdown. Axonal transport impairment, however, may also be caused by aggregation of proteins. Both membrane disruption and protein aggregation can thus converge on the very same common final path having a provenance in completely different pathologies. This illustrates that axonal degeneration cannot be regarded as a uniform sequence of events, but rather should be seen as a process with numerous variants, some of which share common key features.

In the following section, we discuss the neuropathological evidence with respect to axonal degeneration from traumatic, inflammatory and degenerative CNS disorders and their corresponding animal models.

\section{Traumatic CNS disorders}

Traumatic spinal cord injury is a prime example of axonal damage that affects the longest projecting CNS neurons and peripheral afferents. Most cases of traumatic spinal cord injury result in a partial transection of ascending and/or descending tracts and incomplete impairment of sensory or motor functions, whereas only a small fraction represents complete transections (Rowland et al. 2008). Next to the initial axonal damage that occurs because of mechanical stress, secondary damage contributes to further dysfunction (Bramlett and Dietrich 2007). Primary damage to cortical neurons induces Wallerian degeneration of the distal axons projecting to the spinal cord. However, in addition to this direct lesion effect, neighbouring axons that have not been primarily affected show signs of degeneration after a lag period. This is accompanied by a local increase of Iba-1positive microglia, which are hypothesized to be responsible for this secondary damage (Weishaupt et al. 2010).

The spinal cord lesion was also one of the first mammalian animal models in which axonal degeneration could be imaged in vivo. Selective labelling of dorsal root ganglion neurons by using transgenic mice expressing fluorophores in a subset of neurons allowed the visualization of degenerative changes within the first minutes after lesion and permitted the re-imaging of animals several days later. This pioneering technique permitted the identification of acute axonal degeneration (see Acute axonal degeneration) as a separate initial mechanism following traumatic lesions (Kerschensteiner et al. 2005).

Traumatic injury to the brain also results in pronounced axonal lesions, mostly attributable to shear stress (Meythaler et al. 2001). In contrast to focal spinal cord injury, axonal damage in traumatic brain injury is more diffuse. Complete transections are less frequent but the shear stress results in structural damage and bead formation in the axons, which eventually can lead to dysfunction and cell death (McIntosh et al. 1996).

Axonal membrane permeability appears to be rapidly altered after even moderate traumatic brain injury and this is accompanied by a local compaction of neurofilaments (Pettus et al. 1994). In a cat model of fluid percussion brain injury, these local permeability alterations are apparent as early as 5 min after trauma and the decreased spacing of neurofilaments persists at least for $6 \mathrm{~h}$ after the impact (Pettus and Povlishock 1996). Another commonly used model for traumatic brain injury is the stretch injury paradigm in cultured neurons in vitro. Following stretch, undulating distortions are formed along the axons; these are attributable to microtubule breakage and subsequent microtubule loss. Taxol treatment is able to attenuate consequent axonal degeneration, whereas nocodazole treatment promotes it. The downstream cascades of microtubule disruption are likely to involve axonal transport dysfunction (see Axonal transport) and protein accumulation (Tang-Schomer et al. 2010).

\section{Degenerative CNS disorders}

\section{Parkinson's disease}

Many neuropathological studies of PD brains now support the hypothesis that the loss of striatal dopaminergic terminals precedes the demise of dopaminergic neurons in the substantia nigra pars compacta, the demise having long been regarded as the major pathological hallmark of PD (for a review, see Burke 2010). Consistent with this idea, striatal dopamine levels decrease more strongly than the numbers of nigral dopaminergic neurons in PD patients (Kish et al. 1988). Remarkably, the first observable changes in early stage PD brains involve the appearance of Lewy neurites, which initially outnumber Lewy bodies localized in the dopaminergic cell soma (Braak et al. 2003). The axonal projections of the substantia nigra relay an inhibitory signal via dopaminergic transmission to the striatum. However, 
whereas the degeneration of this anatomical projection most prominently reflects the negative motor symptoms in the disease, it is indeed not the only fiber tract affected by degenerative pathology; as could be demonstrated by the studies of Braak and colleagues (2003), degenerative changes appear first in the dorsal motor nucleus of the vagal nerve, spreading further via the caudal raphe nuclei and nucleus coeruleus before reaching the midbrain. Synaptic dysfunction attributable to axonal pathology in the hippocampus and the amygdala of PD patients has been implicated in cognitive and emotional impairment in this disease (Bertrand et al. 2003). More recently, Orimo et al. (2008) have evaluated the degeneration of cardiac sympathetic nerves, which degenerate in PD and in Lewy body disease. Moreover, here, distal axonal degeneration precedes the loss of their mother neurons. Interestingly, alpha-synuclein aggregates are even more frequent in incidental Lewy body disease, in which tyrosine-hydroxylase-positive neurons are still preserved, than in PD patients, which further ferments the discussion of whether Lewy bodies per se are toxic or even protective in aggregopathies. Here, aggregates are predominantly found in the neuronal soma but the number of axons has already decreased markedly (Orimo et al. 2008). These observations in patients with idiopathic PD are similar to those in a brain of a familial PD patient carrying the alpha-synuclein (A30P) mutation (Seidel et al. 2010b). In addition to the degeneration of the nigrostriatal axonal projections, PD patients also show trans-synaptic degeneration, e.g. in the caudate nucleus. This has been made responsible for the poor clinical response of advanced stage PD patients to dopaminergic graft therapy (Lach et al. 1992).

This wealth of data suggests that, in PD, the initially occurring axonal pathology precedes neuronal cell death and that axonal degeneration is the histological substrate of clinically apparent motor and non-motor deficits.

Animal models based on genetic PD forms and toxinbased paradigms also suggest an involvement of axonal pathology in the beginning of the disease process. In a rat model of PD based on adeno-associated virus (AAV)mediated expression of mutant human alpha-synuclein (aSyn.A53T) in the substantia nigra, neuronal loss occurs in a significant manner after 17 weeks. However, well before that, as early as 4 weeks after AAV-injection, dystrophic dopaminergic neurons in the striatum are found and a marked change occurs in proteins with functions in synaptic transmission and axonal transport (Chung et al. 2009). Axonal transport impairment (see Axonal transport) has also been observed in cultured neurons transfected with mutant forms of alpha-synuclein in vitro (Saha et al. 2004). Next to the overexpression of alpha-synuclein, the application of the neurotoxin 1-methyl-4-phenylpyridinium $\left(\mathrm{MPP}^{+}\right)$to primary dopaminergic neurons also leads to significant alterations of axonal transport mechanisms in vitro. Interestingly, $\mathrm{MPP}^{+}$ shows effects on mitochondrial movement, but not on synaptophysin-tagged vesicles or other moving particles, demonstrating that substrate specificity contributes to the particular toxicity of $\mathrm{MPP}^{+}$in axons. In this model, neurite degeneration and an induction of autophagy (see Autophagy and the ubiquitin-proteasome system) also occur before cell body loss (Kim-Han et al. 2011).

Autosomal-dominant mutations in leucine-rich repeat kinase 2 (LRRK2) belong to the most frequent causes of familial PD. Large genome-wide association studies have identified LRRK2 in addition to alpha-synuclein as an important risk locus for the development of PD (SimónSánchez et al. 2009; Satake et al. 2009). Even the initial reports of LRRK2 function implied a role in neurite growth for this large multidomain protein (Macleod et al. 2006). In Drosophila, overexpression of the pathogenic LRRK2 (G2019S) mutant results in mislocalization of tau protein in dendrites and causes dendrite degeneration. The mechanism is suggested to involve an increased recruitment of the Drosophila glycogen synthase kinase 3 (GSK-3 $\beta$ ) homolog (shaggy) by LRRK2 (G2019S), which in turn induces hyperphosphorylation and mislocalization of tau (Lin et al. 2010). Overexpression of the human mutant LRRK2 (R1441G) in a bacterial artificial chromosome transgenic mouse model supports the role of this protein in axonal stability. In addition to levodopa-sensitive motor symptoms, which have been observed at 10 months of age, these animals present fragmented dopaminergic axons, axonal spheroids and dystrophic neurites ( $\mathrm{Li}$ et al. 2009). As can also be shown in SH-SY5Y cells in vitro, overexpression of mutant LRRK2 (G2019S) results in decreased neurite outgrowth and an increased number of autophagic vacuoles (see Autophagy and the ubiquitin-proteasome system) and this effect is mediated by mitogen-activated protein kinase (MAPK)/extracellular signal-regulated kinase (ERK) signalling (Plowey et al. 2008).

Models based on alpha-synuclein, LRRK2 or 1-methyl4-phenyl-1,2,3,6-tetrahydropyridine (MPTP)/MPP ${ }^{+}$appear substantially different at first glance and all these models only partially reproduce the pathophysiology of human PD. However, alterations in axonal transport, autophagy and an early axonal loss preceding cell death seem predominantly common themes that can be partially correlated to autopsy material suggesting an involvement of these processes in the human disease. Thus, the hope is raised that the targeting of any of these mechanisms in a therapeutic manner will modify the disease progression in humans independently of the underlying etiology.

\section{Amyotrophic lateral sclerosis}

Axonal degeneration in amyotrophic lateral sclerosis (ALS) has long been considered to occur only as a secondary 
process, the result of motoneuron apoptosis comparable to Wallerian degeneration (Przedborski 2004). Thus, the "dying-forward" hypothesis proposes that ALS is mainly a disorder of cortical motoneurons that connect monosynaptically with anterior horn cells and mediate anterograde degeneration of anterior horn cells via glutamate excitotoxicity. However, several animal studies have recently demonstrated that the exclusive protection of the neuronal cell body, e.g. through the regulation of pro- or anti-apoptotic proteins such as $\mathrm{Bax}$ or $\mathrm{Bcl}-2$, does not prevent axonal degeneration or functional deterioration (Sagot et al. 1995; Gould et al. 2006). Even stronger evidence comes from human autopsy material. Fischer and colleagues (2004) have impressively demonstrated, in autopsy material from an ALS patient who died from an unrelated cause only 6 months after symptom onset, that denervation and reinnervation were pronounced, while the spinal motor neurons were not yet affected. Pathological examination of tissue from ALS autopsy cases and from transgenic mouse models of the disease demonstrates the appearance of swollen axonal segments or spheroids being rich in intermediate filament proteins including the neurofilament triplet proteins NFL, NFM and NFH (Hirano 1996). The pathophysiology that leads to the formation of these spheroids is most likely linked to axonal transport deficits (see Axonal transport) as has been shown in various mouse models (Rao and Nixon 2003). Recently, data from a cell culture model of axonopathy with spheroid formation, neurofilament and microtubule disorganization have underlined the important influence of the glial environment on the disruption of axonal transport (King et al. 2011). Hence, (1) the mechanisms of neuronal cell body demise must differ from axonal degeneration and the latter cannot be explained as a pure consequence of the somatic dysfunction and (2) axonal degeneration seems to precede neuron death in this disease, suggesting an additional "dying back" mechanism (for reviews, see Rowland and Shneider 2001; Fischer and Glass 2007).

This is also reflected in the SOD1 (G93A) mouse model of ALS, which is based on a mutation found in familial ALS cases and faithfully reproduces the clinical course of disease in humans (Gurney et al. 1994). Because of a clearly defined age at symptom onset, SOD1 (G93A) mice are an ideal model for the study of the presymptomatic alterations in this motoneuron disorder. Paralleling the findings from autopsy material, SOD1 (G93A) mice show a dramatic denervation of motor end plates well before the onset of clinical disease; whereas motor weakness starts to be apparent only at around 80 days, about $40 \%$ of the neuromuscular junctions show denervation. However, at this time, no evidence for motoneuron cell loss is detectable (Fischer et al. 2004). The situation seems to be slightly different for corticospinal motoneurons. In the same SOD1 (G93A) model, early and cell-type specific apoptosis has been observed among neocortical neurons. Here, the degeneration of the corticospinal tract appears to follow neuronal demise, which can be visualized by using double-transgenic Thy1-YFP/ SOD1 (G93A) mutants (Ozdinler et al. 2011). A recent study by Bilsland et al. (2010) clearly demonstrates that axonal transport deficits occur in presymptomatic mice and represent the earliest axonal pathologies in this model, occurring well before motoneuron loss.

In conclusion, data from ALS and motoneuron disease models suggests that axonal degeneration probably precedes motoneuron death. This obviously does not exclude the presence and negative additional impact of somatic dysfunction on disease progression.

\section{Alzheimer's disease}

One of the prominent neuronal structural alterations in $\mathrm{AD}$, other than amyloid plaques and neurofibrillary tangles, are dystrophic neurites (Onorato et al. 1989). These neurites are characterized by the disorganization of the microtubule and the neurofilament network (Boutajangout et al. 2004) and the abnormal accumulation of variably phosphorylated neurofilaments that can be found even in early stages of the disease (Dickson et al. 1999). A recent study in human patients with mild cognitive impairment and early $\mathrm{AD}$ has visualized functionally relevant alterations of the axonal tracts in the white matter of the brain by employing diffusion tensor imaging, thereby confirming that axonal degeneration is a measurable pathological feature even at early stages of this disease in humans (Huang et al. 2007).

Moreover, a number of animal models for $\mathrm{AD}$ have been developed and extensively studied as a surrogate for neuropathological alterations observed in human patients. Pronounced axonal degeneration has been reported for most of these models, including models with underlying mutations of tau (Probst et al. 2001), ApoE (Tesseur et al. 2000), and amyloid precursor protein (APP; Wirths et al. 2007), to name only a few examples. These axonal defects are typically characterized by large axonal swellings, often in close proximity to the amyloid plaques (Stokin et al. 2005). For example, in 5XFAD mice expressing a triple-mutated human APP, prominent axonal swellings are found in the brain and spinal cord even at 3 months of age (Jawhar et al. 2010). Many dystrophic neurites can be seen close to extracellular plaques. The motor deficits observed in these mice correlate with the formation of axonal spheroids in the brain and spinal cord (Oakley et al. 2006; Jawhar et al. 2010). The interaction of extracellular plaques and the intra-axonal milieu is a matter of intense current research and a better understanding of this interaction might shed light on the function of protein aggregates for axonal degeneration in a number of aggregopathies. 


\section{Chronic inflammatory CNS disorders}

For decades MS, as the prime example for chronic inflammatory CNS disorders, has been regarded as a largely demyelinating disorder. However, studies of brain tissue from MS patients have changed this picture completely; axonal transections with morphological changes resembling traumatic axonal injury, such as axonal ovoids, are abundantly present in acute and chronic lesions (Ferguson et al. 1997; Trapp et al. 1998). Characteristics of Wallerian degeneration can be identified in the periplaque white matter in early MS, reaffirming the finding that axonal lesions represent the morphological correlate of the persistent neurological deficits in MS patients (Dziedzic et al. 2010).

Animal models of MS, such as the experimental autoimmune encephalomyelitis (EAE) model induced by immunization with myelin oligodendrocyte glycoprotein, show axonal degeneration as an important feature and this can even precede the demyelinating component (D. Wang et al. 2005). Using multiphoton in vivo imaging techniques, Nikić et al. (2011) have been able to demonstrate that focal axonal degeneration (FAD, see Chronic axonal degeneration) might precede demyelination in a mouse model of MS. Focal intraaxonal mitochondrial alterations can be observed, even before the ultrastructural signs of axonal damage. In this model, reactive oxygen and nitrogen species, which are likely to be derived from activated macrophages, are able to initiate mitochondrial damage and FAD. Most intriguingly, the authors have been able to show that these initial axonal alterations can be reversible up to a certain time point, opening a novel window for intervention. Similar changes have also been observed in human biopsy tissue of MS patients underlining the importance of these findings (Nikić et al. 2011).

\section{Mechanisms of axonal degeneration}

In this section, we will first describe basic concepts of axonal demise; these concepts are initially described based on their morphological and temporal characteristics. Secondly, we will take a closer look at the molecular mechanisms underlying axonal damage, thereby making clear that such mechanisms can represent underlying events of morphologically different degenerative processes.

\section{Mechanistic concepts}

Like apoptosis, most forms of axonal degeneration seem to be active self-destructing cellular processes involving a determined cascade of various molecular players (Raff et al. 2002). We need however to note that apoptosis and axonal degeneration employ independent biochemical pathways and can be initiated and modulated separately (Whitmore et al. 2003). Different forms of axonal degeneration have been described with regards to localization on the axon and time kinetics. Although common molecular convergence points probably exist, important mechanistical differences are found between each type of axonal degeneration. The most extensively studied form of axonal degeneration is the sequential degeneration following a traumatic lesion of an axon. This includes acute axonal degeneration in the vicinity of the lesion and Wallerian degeneration of the distal part of the axon. The study of axonal degeneration in chronic neurological diseases represents a greater challenge as this process does not occur simultaneously in all axons of a certain tract and often proceeds over extended time periods. Nevertheless, FAD, axonal die-back and Wallerian degeneration have been described for these conditions.

\section{Acute axonal degeneration}

The term acute axonal degeneration refers to a rapid axonal disintegration within several hours following a traumatic lesion in the CNS. It is confined to the adjacent 300 $400 \mu \mathrm{m}$ of the proximal and distal end of the axon and has been described for the spinal cord (Kerschensteiner et al. 2005) and the optic nerve (Knöferle et al. 2010). In both cases, it has been visualized by using in vivo live-imaging techniques. Although the time kinetics differ slightly between the model systems, being faster in the mouse spinal cord than in the rat optic nerve, the sequential morphological changes and the undelying mechanisms seem to be similar in both tissues (summarized in Fig.1).

At first, for 10-30 min after a traumatic lesion, the axon remains completely stable with regard to its macroscopic morphological appearance. On the molecular level, however, a signalling cascade has already been activated, finally resulting in the fragmentation of the axon. It is initiated by a rapid calcium influx into the axon and a consecutive transient rise of the axoplasmic calcium concentration within $40 \mathrm{~s}$ after lesion (see Calcium). Application of calcium channel inhibitors at the time of the lesion blocks this rise in cytosolic calcium and almost completely inhibits acute axonal degeneration (Knöferle et al. 2010). The calcium influx leads to an activation of the calcium-sensitive protease calpain, which reaches its maximum $30 \mathrm{~min}$ after the lesion. Local application of calpain inhibitors can completely inhibit consecutive acute axonal degeneration (Kerschensteiner et al. 2005). Calpain regulates a multitude of neuronal substrates (for a review, see Vosler et al. 2008) but which of these are most relevant for axonal degeneration is currently still under investigation (see Calcium-triggered events).

The first changes at the ultrastructural level become visible within the first $30 \mathrm{~min}$ after lesion and consist of the condensation and misalignment of neurofilaments 
Fig. 1 a Micrographs of a rat optic nerve axon labelled with enhanced green fluorescent protein expressed by an intravitreally injected viral vector at given time points (in min) after optic nerve crush (proximal to the crush site). $\mathbf{b}$ Quantification of the axonal integrity ratio (sum length of the remaining axonal fragments divided by initial length of the intact axon segment) of the axon in a. c Representation of the morphological events observed in acute axonal degeneration. A crush lesion of an axon of the central nervous system leads to a rapid increase of intracellular calcium concentrations within the first 30-40 s after lesion. Misalignment of neurofilaments and disruption of microtubules followed by local accumulations of organelles attributable to dysfunctional axonal transport and the subsequent formation of axonal bulbs can be seen within the next $30-120 \mathrm{~min}$. This is then followed by the appearance of a high number of autophagic vacuoles and the fragmentation of the axon spanning over $400 \mu \mathrm{m}$ proximal and distal from the crush site a

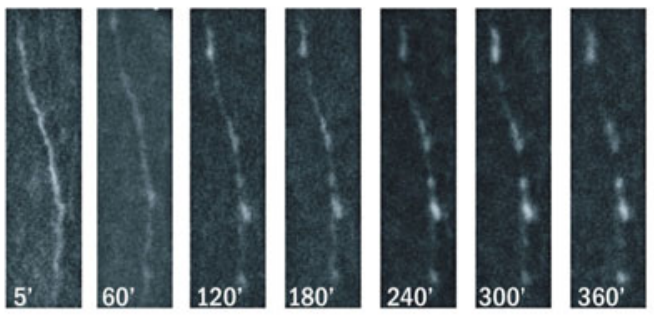

b

C
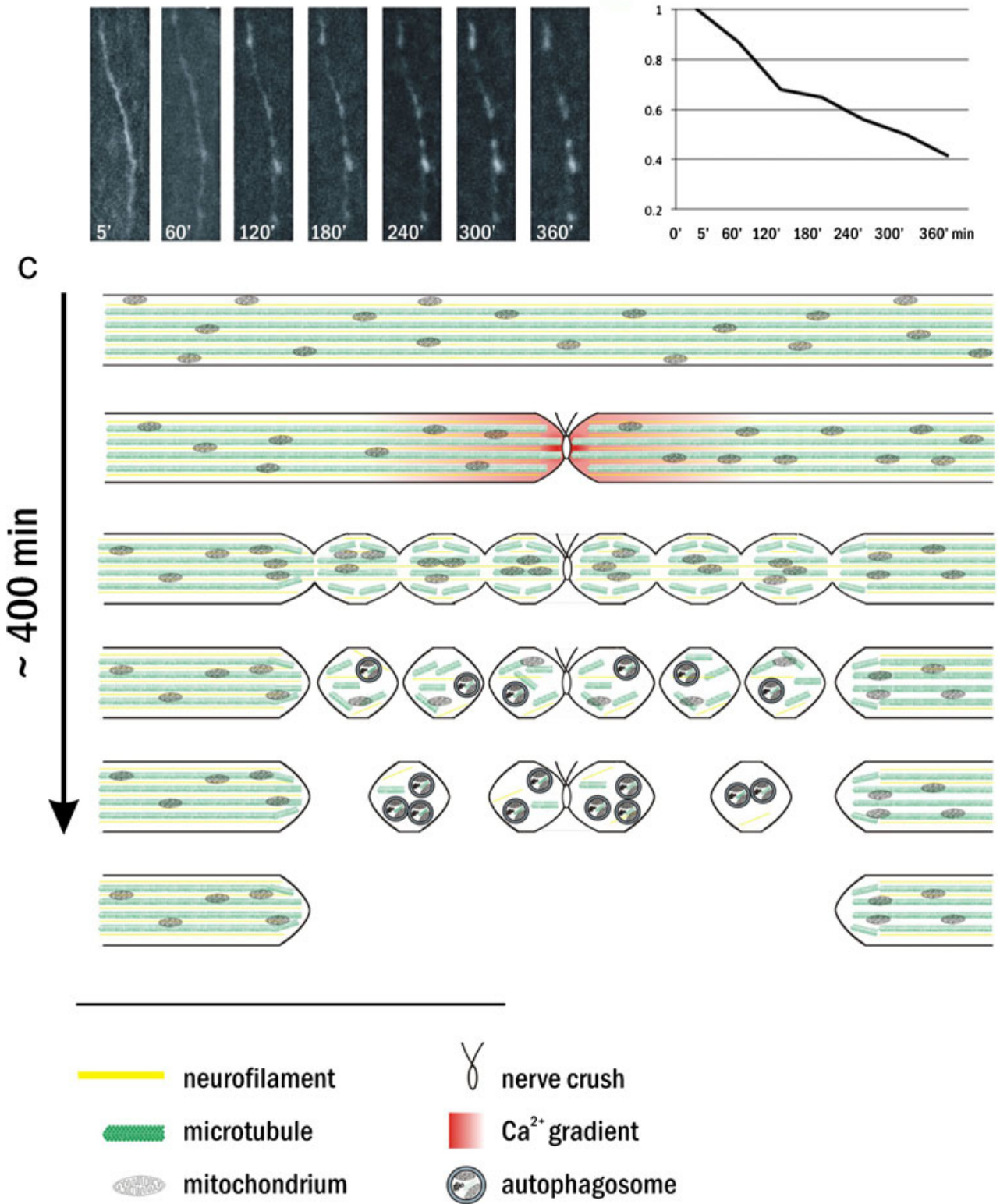

followed by the fragmentation of microtubules (Knöferle et al. 2010). Both focal neurofilament compaction and microtubular proteolysis have been linked to calpain activation in other disease models in the CNS, and the ERK/MAPK pathways have been suggested as molecular mediators (Pettigrew et al. 1996; Veeranna et al. 2004). Therefore, the initial calpain activation might also be responsible for these early ultrastructural changes in acute axonal degeneration. Moreover, the rapid breakdown of the cytoskeleton probably leads to the early impairment of axonal transport. Indirect signs in favour of this assumption are accumulations of organelles, mainly mitochondria and vacuoles, eventually leading to local axonal swellings that can be found early in axons undergoing acute axonal degeneration (Knöferle et al. 2010).
Another characteristic ultrastructural feature of acute axonal degeneration is a local activation of autophagy (see Autophagy and the ubiquitin-proteasome system). The number of autophagosomes in the axon significantly increases within the first $6 \mathrm{~h}$ after lesion. Pharmacological inhibition of autophagy markedly attenuates acute axonal degeneration but this effect, however, is not as pronounced as after calcium channel blockage. The latter not only inhibits acute axonal degeneration, but also reduces autophagy, suggesting that autophagy is a downstream target of calcium influx (Knöferle et al. 2010; Koch et al. 2010).

Whereas pharmacological interventions such as the inhibition of calcium, calpain and autophagy are highly effective in preventing acute axonal degeneration, the long-term effects of these treatments are still unclear. As acute axonal 
degeneration only affects $\sim 400 \mu \mathrm{m}$ of the axon proximal to the lesion site, the direct functional benefit of rescuing this short portion of the axon is negligible. Nevertheless, one can argue that the regenerative response of a lesioned axon might be fostered as the distance to the rapidly forming, growth-inhibiting scar tissue becomes smaller. Kerschensteiner et al. (2005) have shown that regenerating sprouts can be seen within $24 \mathrm{~h}$ after lesion. Although these early axonal sprouts lack appropriate directional information, they could possibly benefit from an inhibited acute axonal degeneration; this however remains to be experimentally established.

\section{Wallerian degeneration}

Wallerian degeneration classically refers to the degeneration of axons distal to a lesion site (Waller 1850). After a traumatic lesion, the parts of the axon that are not affected by acute axonal degeneration initially stay morphologically stable for the first 24 to $72 \mathrm{~h}$. Then, the distal part of the axon undergoes a progressive fragmentation that resembles the fragmentation seen in acute axonal degeneration (Kerschensteiner et al. 2005) and that finally leads to a complete removal of the distal part of the axon. Wallerian degeneration proceeds directionally along the axon with a speed ranging from $0.4 \mathrm{~mm} / \mathrm{h}$ in cultured primary neurons (Sievers et al. 2003) to $24 \mathrm{~mm} / \mathrm{h}$ in the mouse sciatic nerve (Beirowski et al. 2005). In the peripheral nervous system, the direction of Wallerian degeneration on the axon seems to depend on the lesion type; complete transection of the nerve leads to an anterograde fragmentation proceeding from proximal to distal, whereas a crush lesion results in retrograde fragmentation starting at the far distal end of the axon (Beirowski et al. 2005). Although macrophages and glia play an important role, especially in the final removal of the axon fragments, the mechanism of Wallerian degeneration seems to be intrinsic to the axon (Glass et al. 1993; Hoopfer et al. 2006; MacDonald et al. 2006).

The molecular machinery underlying Wallerian degeneration is still not completely understood, although great progress has been made with the help of the so-called WldS mouse (Lunn et al. 1989). In this mouse mutant, axon stumps distal to the lesion site survive ten times longer than axons in wild-type animals, while the survival of the neuronal cell body is not altered (Deckwerth and Johnson 1994; Adalbert et al. 2006).

The mutant protein WldS, which is responsible for slowing down the degenerative process in WldS mice, is a chimeric gene product consisting of a fragment of the polyubiquitination factor UFD2a/UBE4b and the full-length nicotinamide mononucleotide adenylyltransferase-1 (NMNAT1; Mack et al. 2001). NMNAT1 is a key protein of the nicotinamideadenine dinucleotide ${ }^{+}\left(\mathrm{NAD}^{+}\right)$salvage pathway in mammals.
UBE4b is an E4-type ubiquitin ligase that can add multiubiquitin chains to substrates of the ubiquitin/proteasome degradation pathway (Hatakeyama et al. 2001). The functionally most important molecular sites of WldS are the ATPbinding site and the $\mathrm{NMN}^{+}$binding site of NMNAT1 and the valosin-containing protein (VCP)-binding site of UBE4b, as has been shown by knock-out experiments. Both a functional NMNAT1 and a functional UBE4b fragment seem to be required for the neuroprotective action of WldS. This is suggested by the observation that, although disruption of the enzymatic activity of NMNAT1 in transgenic WldS mice results in a strongly reduced neuroprotective phenotype (Avery et al. 2009; Conforti et al. 2009; Yahata et al. 2009), the overexpression of NMNAT1 alone is not sufficient to protect lesioned axons from degeneration in mammalian neurons (Conforti et al. 2009). Moreover, NMNAT-1 has been demonstrated to function not only with enzymatic activity, but also as a chaperone, at least in biochemical assays and cultured cells (Zhai et al. 2003).

The WldS protein is located mainly in the nucleus but has also been detected in the axoplasm and axoplasmic organelles (Beirowski et al. 2009; Yahata et al. 2009). Local overexpression of NMNAT1 targeted to the axonal compartment results in protective effects resembling those of the WldS transgene (Beirowski et al. 2009; Sasaki et al. 2009a; Babetto et al. 2010). These data suggest that the protective action of WldS is mediated by the continuous transport of the protein along the axon. In agreement with this, other NMNAT isoforms have been shown to promote axonal survival locally. NMNAT2 is continuously transported from the cell body to the axon and has an extremely short turnover time of $\sim 4 \mathrm{~h}$ (Gilley and Coleman 2010). Short interfering RNA (siRNA)-mediated downregulation of NMAT2 or inhibition of its transport to the axon lead to the induction of axonal degeneration, whereas overexpression delays axotomy-induced degeneration (Gilley and Coleman 2010; Yan et al. 2010). Similar positive effects on axonal survival and integrity can be achieved by the overexpression of the mitochondrial isoform NMNAT3 (Avery et al. 2009; Yahata et al. 2009). The downstream targets of the NMNAT isoforms for promoting axonal survival still remain elusive. All NMNATs contain a catalytic domain for the synthesis of $\mathrm{NAD}^{+}$(Berger et al. 2005). The data concerning the role of $\mathrm{NAD}^{+}$in the maintenance of axonal survival are however inconsistent. Extracellular application of high concentrations of $\mathrm{NAD}^{+}$result in the protection of injured axons in vitro, whereas various attempts to increase the intracellular $\mathrm{NAD}^{+}$concentration have not had an effect on axonal degeneration (Sasaki et al. 2009b). The local action of $\mathrm{NAD}^{+}$in subcellular departments within the axon involving local energy supply (J. Wang et al. 2005), the local sequestering of $\mathrm{Ca}$ ions or the modulation of ion channel activity (Tamsett et al. 2009) have been argued to account for 
$\mathrm{NAD}^{+}$-mediated effects in the axon but these hypotheses still need to be established by experimental evidence.

\section{Chronic axonal degeneration}

The time kinetics of axonal degeneration in chronic neurodegenerative diseases are more challenging to study. However, various morphological forms of axonal degeneration have been described for these conditions that may also occur in parallel.

The first type is termed "dying back degeneration" (Cavanagh 1964). This form of degeneration has been described in ALS (Sobue et al. 1983; Nihei et al. 1993), diffuse Lewy body disease (Iseki et al. 1998), spinocerebellar ataxia (Seidel et al. 2010a), peripheral neuropathies (Vavlitou et al. 2010) and toxic neuropathies (Bennett et al. 2011), amongst others. It is initiated by a dysfunction of the synaptic connection and/or a degeneration of the distal regions of the axon. This is then followed by a degeneration of the whole axon in a distal-to-proximal direction, finally leading to a fragmentation of the axon morphologically resembling that of Wallerian degeneration (Cavanagh 1979). The biochemical mechanisms underlying this form of degeneration are currently not completely clear but synaptic pathology (Chang et al. 2006), mitochondrial dysfunction (Shi et al. 2010) and disturbances of axonal transport (Morfini et al. 2007; Bilsland et al. 2010) have been implied.

Dying back degeneration shares striking similarities with axonal pruning and axosome shedding, a process that is observed for example in the developmental maturation of the neuromuscular synapse or target selection, e.g. by retinal ganglion cell axons (for excellent reviews, see Luo and O'Leary 2005; Misgeld 2011).

Another form of axonal degeneration has been recently visualized in a model of chronic inflammatory disease: FAD. Morphologically, a focal swelling of the axon is observed at the beginning and is characterized by an accumulation of organelles and dysmorphic mitochondria. This focal swelling is accompanied by a dysfunction of axonal transport and eventually leads to a local disruption of the axon followed by a Wallerian-like fragmentation of the axon stumps. FAD has recently been imaged in vivo in an animal model of MS (Nikić et al. 2011). In this EAE model, increased levels of reactive oxygen species in the inflammatory EAE lesions are able to induce focal axonal swellings and these have been shown to be partially reversible (see Chronic inflammatory CNS disorders).

The underlying molecular machinery

Acute axonal degeneration, focal axonal degeneration and Wallerian degeneration appear to be specific morphological expressions of a cumulative number of underlying molecular mechanisms. We review here some of the most important and so far best-characterized molecular mechanisms that form the backbone of the degenerative cascade (summarized in Fig. 2).

\section{Calcium}

Several means have been experimentally shown to contribute to the elevation of axoplasmic calcium concentration in various lesion paradigms: (1) calcium influx from the extracellular space through disrupted membranes, (2) calciumchannel-mediated calcium influx from the extracellular space and (3) release of calcium from intracellular calcium stores (for a comprehensive review, see Stirling and Stys 2010).

Mechanical axonal lesions result in the disruption of the membrane continuity and subsequent influx of extracellular calcium into the cytoplasm. As Ziv and Spira (1995) have demonstrated using calcium-sensitive dyes in cultured Aplysia axons in vitro, the calcium wave induced through the transection of one neurite branch rapidly spreads, within seconds, until the next branching point where it seems to be halted. Intra-axonal calcium concentrations decrease subsequently within several minutes reaching initial levels after the resealing of the lesioned axon end. However, intracellular calcium concentrations reach a maximum of up to $>1 \mathrm{mM}$ near the lesion site and of up to several hundred micromolar more distal from it (Ziv and Spira 1995). Axotomy-induced calcium increase in vitro has been shown to require extraaxonal calcium levels of $>200 \mu \mathrm{M}$ and calcium has been demonstrated to enter axons via L-type, but not N-type calcium channels in dorsal root ganglion axons (George et al. 1995). Studies of the rat optic nerve however have suggested the additional involvement of other calcium channels (P/Q-type, N-type) in the mediation of calcium influx into the lesioned axon (Fern et al. 1995; Alix et al. 2008), suggesting that the results depend on the examined region of the nervous system.

The extra-axonal space appears to be not the only source of calcium, as has been demonstrated by studies employing a calcium-depleted extracellular medium. Here, axonal damage can equally elicit an intra-axonal calcium increase demonstrating that intracellular calcium stores can also contribute to cytoplasmic calcium release. For example, in ischaemic damage of dorsal column axons, calcium has been shown to be released from the endoplasmic reticulum through ryanodine receptors (Ouardouz et al. 2003) or from mitochondria (Nikolaeva et al. 2005).

In myelinated axons, ryanodine receptors can be activated through L-type Ca channels, similar to so-called excitationcontraction coupling in skeletal muscle cells. Both ryanodine receptors and L-type $\mathrm{Ca}$ channels seem to be colocalized near 
Fig. 2 Representation of selected molecular mechanisms involved in axonal degeneration. Intra-axonal calcium levels can rise by the entry of calcium from the extra-axonal space, e.g. through calcium channels and disrupted axonal membranes, and from intra-axonal sources, e.g. mitochondria or endoplasmic reticulum (not shown). Calcium-dependent proteins, such as calpain, are activated and cleave target proteins, e.g. microtubules or collapsin response mediator protein-2 $(C R M P-2)$. This in turn can result in axonal transport impairment. Autophagy is induced in a calcium-dependent manner and results in the degradation of proteins and organelles

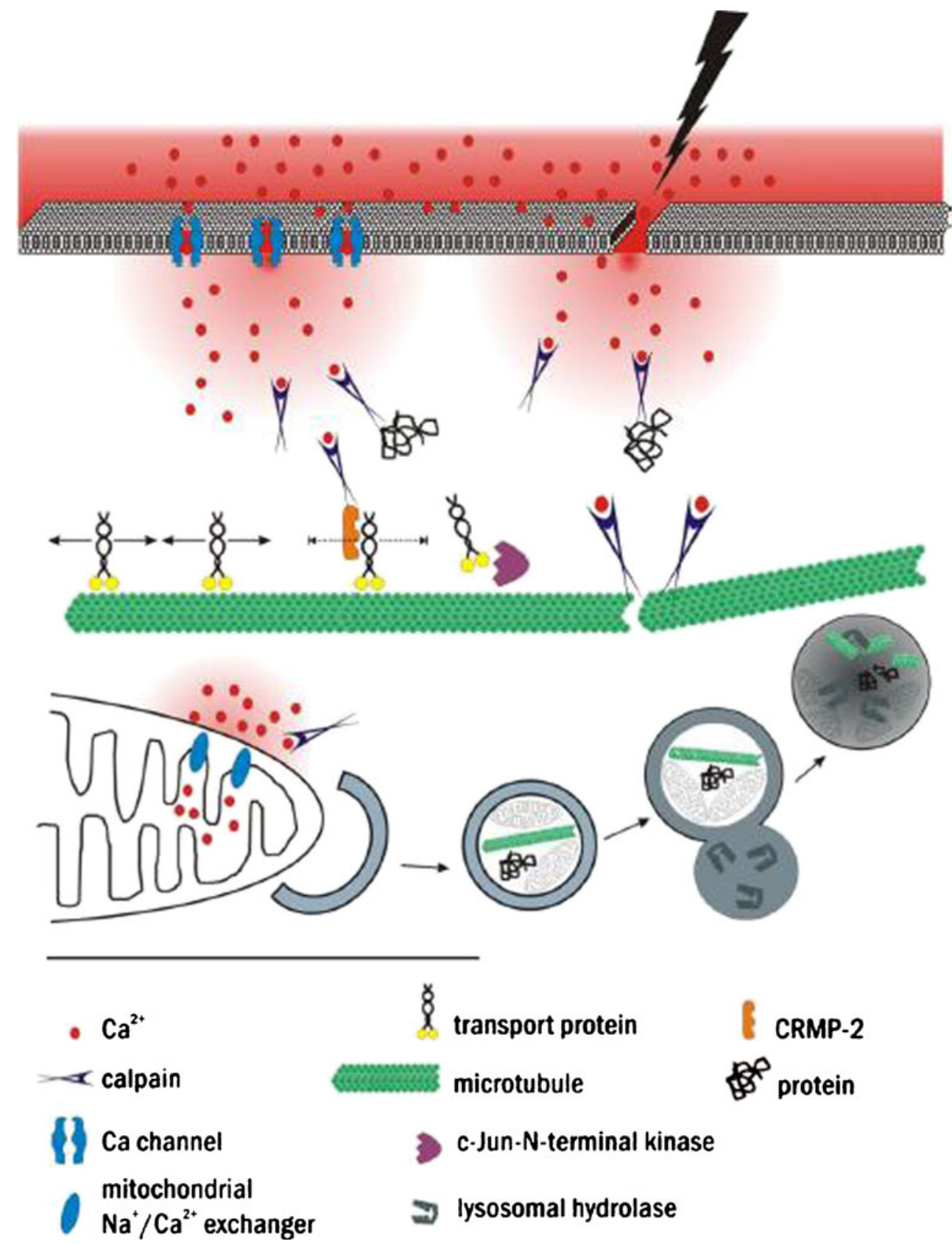

the axolemma of myelinated axons. However, the blockage of intra-axonal calcium release, e.g. through the L-type calcium channel blocker nimodipine, only partially protects axons from degeneration suggesting that other sources of calcium or other non-calcium-dependent mechanisms contribute to axonal degeneration (Ouardouz et al. 2003). For example, intra-axonal calcium levels are known to increase when an ischaemia- or hypoxia-induced lack of energy supply results in the breakdown of the $\mathrm{Na}^{+} / \mathrm{Ca}^{2+}$ exchanger (Stys et al. 1992). In ischaemia, the majority of the intra-axonal calcium release appears to be mediated through the $\mathrm{Na}^{+} / \mathrm{Ca}^{2+}$ exchanger as can be demonstrated in experiments with CGP37157, a blocker of the $\mathrm{Na}^{+} / \mathrm{Ca}^{2+}$ exchanger in mitochondria (Nikolaeva et al. 2005). In this model, the application of cyclosporine A, a blocker of the mitochondrial permeability transition pore (mPTP), does not provide sufficient protection, thereby arguing against mPTP involvement. However, as Barrientos et al. (2011) have recently demonstrated in another model, the last word on the role of MPTP in axonal demise has not yet been spoken; axons in optic nerve explants show less mitochondrial swelling after the application of cyclosporine A and are indeed protected from degeneration. This effect has been further pinned down to the function of cyclophilin D (CypD), a component of the MPTP in neurons, the axons of which are protected after siRNA-mediated depletion of CypD (Barrientos et al. 2011). 
Finally, excess calcium in neurons can be extruded by membrane-located pumps, such as the plasma-membrane calcium ATPase isoform 2. A decrease in the levels of this pump can promote axonal pathology in animal models of MS (EAE) and spinal cord injury (Nicot et al. 2003; Kurnellas et al. 2005).

\section{Calcium-triggered events}

Calcium influx is followed by the activation of calciumdependent proteases, such as calpains, which cleave and degrade cytoplasmic proteins. An increased activity of calpains has been demonstrated for diffuse axonal injury following brain trauma and also in stroke, spinal cord injury and neurodegenerative diseases (Kampfl et al. 1996; Vosler et al. 2008). Calpains can proteolytically degrade a plethora of targets, such as cytoskeletal proteins, enzymes, receptors, channels and transcription factors (for a review, see Saatman et al. 2010). As such, calpains have also been shown to degrade substrates of crucial importance to axonal stability. Neurite degeneration as a result of growth factor deprivation (e.g. of nerve growth factor) also leads to calpain activation. This is followed by proteolytic cleavage of the collapsin response mediator protein-2 (CRMP-2; Touma et al. 2007). Because CRMP-2 binds to kinesin-1 and participates in axonal transport, cleavage by calpain interferes with cargo delivery (see Aggregation under Therapeutic targets).

In addition to calpain, other calcium-dependent enzymes are known to participate in axonal degeneration. For example, transient axonal stretch injury in vitro results in calcium release primarily from intracellular stores and this is followed by a delayed intracellular calcium level rise over $48 \mathrm{~h}$. Here, the inhibition of the calcium-dependent phosphatase calcineurin attenuates secondary axonal degeneration (Staal et al. 2010). Calpain and calcineurin are only two examples of calcium-dependent proteins that act further downstream and that have been studied in more detail in this context.

\section{Mitochondrial damage}

Mitochondria appear to take a key role in the initial localization of axonal continuity disruption. In models of traumatic brain injury in which diffuse axonal injury is a major pathophysiological component, calcium influx is thought to be mediated through axolemmal pores. However, axonal damage and calpain activation does not occur simultaneously over the entire length of the axon but shows focal peaks colocalizing with mitochondria (Kilinc et al. 2009). This focal accumulation of mitochondria might be attributable to focal disruption of the cytoskeleton and cargo accumulation but could equally contribute to a further focal increase in calcium levels from accumulating mitochondria (see Calcium).

In $\mathrm{FAD}$, mitochondria are damaged by reactive oxygen and nitrogen species, which are likely to be derived from macrophages, and this again triggers further axonal degeneration (Nikić et al. 2011). As mentioned earlier (see Calcium), the activation of the MPTP seems to play a pivotal role in triggering axonal destruction in axons of the CNS and peripheral nervous system (PNS) axons (Barrientos et al. 2011). In a model of familial ALS, mitochondria seem to participate in apoptotic cell death and consequent axonal degeneration, because the deletion of two neuronal pro-apoptotic $\mathrm{Bcl}-2$ family members, Bax and Bak, is able to prevent axonal degeneration (Reyes et al. 2010). The debate on the relevance of mitochondrial motility is not completely settled as yet, since reports have also demonstrated that increased mitochondrial transport, as observed in syntaphilin knock-out mice, does not support survival in the SOD1 (G93A) mouse model (Zhu and Sheng 2011). On the other hand, motility impairment has been shown in a model of Huntington's disease in which mutant huntingtin interacts with the mitochondrial protein Drp1 and results in defective mitochondrial movement and synaptic deficiencies (Shirendeb et al. 2011). Amyloidbeta $(A \beta)$ has recently also been shown to impair mitochondrial motility and neurons treated with $A \beta$ have shorter mitochondria, a feature that eventually results in synaptic degeneration (Calkins and Reddy 2011). Even more evidence comes from a histological study in brain samples of MS patients with chronic and active lesions in which alterations in mitochondrial density and function have been detected. Here, the activity of the mitochondrial respiratory chain complex IV has been shown to be reduced in demyelinated axons at the active edge of chronic active lesions but, interestingly, in chronic lesions, complex IV activity and mitochondrial mass are increased, possibly because of adaptive processes occurring during disease progression (Mahad et al. 2009).

The above-mentioned findings are only a few examples underlining that alteration of mitochondrial function, mitochondrial trafficking and activation of the mitochondrial apoptotic pathway, all of which might contribute to axonal damage in the different contexts of CNS pathology. A local lack of energy supply attributable to mitochondrial failure and a local increase of calcium concentrations might both be crucial factors.

\section{Aggregation}

Amyloidogenic proteins, such as alpha-synuclein, tau and $\mathrm{A} \beta$, have been suggested to promote axonal degeneration in several neurodegenerative disorders, e.g. through interference with axonal transport mechanisms. Of course, the aggregation of proteins does not occur in all paradigms of axonal degeneration but it may promote axonal pathology in 
aggregopathies. For example, the overexpression of human wild-type alpha-synuclein by lentiviral vectors has recently been shown to result in aggregation and a clear degenerative phenotype in CNS axons (Decressac et al. 2011). Aggregation of amyloidogenic proteins cannot be regarded as a stand-alone phenomenon, since recent data have demonstrated that increased calcium concentrations accelerate alpha-synuclein aggregation in solution and in cultured cells (Nath et al. 2011). Thus, we can hypothesize that axonal lesions with consequent calcium influx also drives the aggregation of amyloidogenic proteins. Vice-versa, the presence of alpha-synuclein itself appears to influence traumainduced axonal degeneration. Transgenic mice overexpressing the human alpha-synuclein (Thy $1-\alpha \mathrm{Syn}_{\mathrm{WT}}$ ) possess alpha-synuclein aggregates in the axons of the sciatic nerve. These animals display increased Wallerian degeneration after axotomy of the sciatic nerve, whereas in mice without alpha-synuclein expression (C57BL/6-Ola-hsd strain by Harlan B6), axonal degeneration occurs at a significantly slower rate (Siebert et al. 2010). This is intriguing, because alpha-synuclein is predominantly attributed a function in neurodegeneration of the CNS. This study, however, suggests that alpha-synuclein is involved in a more general mechanism of axonal destruction, which is also important for the PNS and traumatic lesions, and might be independent of a chronic neurodegenerative process per se. Its precise mode of action is as yet unresolved but accumulating data have led to the proposal of a direct interaction with the cytoskeleton; the colocalization of alpha-synuclein has been reported not only with cytoskeletal proteins, such as neurofilaments, tau and tubulin (Jensen et al. 1999; Alim et al. 2002; Kanazawa et al. 2008), but also for transport proteins, such as dynein and kinesin-1 (Utton et al. 2005).

Axonal inclusions have also been found in brains of patients with spinocerebellar ataxia type-3 (SCA3). Ubiquitin-positive aggregates have been observed in axonal projections that are known to degenerate in SCA3 patients. It is likely that these aggregates are detrimental to axonal transport mechanisms; this however remains to be established (Seidel et al. 2010a). Similar evidence comes from animal models of Huntington's disease. Here, axonal accumulations of aggregated huntingtin result in transport defects that precede neuronal cell death ( $\mathrm{Li}$ et al. 2001).

In $\mathrm{AD}, \mathrm{A} \beta$ has been identified as one of the main mediators of axonal degeneration (Yankner et al. 1990; Emre et al. 1992). In vitro, the exposure of cultured rat sympathetic neurons to $A \beta$ induces axonal degeneration, which only in the second place triggers the activation of caspases and subsequent neuronal cell death. This observation supports the hypothesis of primary axonal degeneration as being an important step in the pathogenesis of AD. In vivo, the clear spatial association of axonal swellings and dystrophic neurites with amyloid plaques points to a causal relationship between $A \beta$ and axonal degeneration (Stokin et al. 2005). Transcranial two-photon imaging in vivo has been able to visualize dendritic damage by amyloid deposits near neurites; such damage leads to spine loss, shaft atrophy, varicosity formation and finally continuity disruption (Tsai et al. 2004). This is further strengthened by studies demonstrating that injections of $A \beta$ in brains of normal rats can induce neurodegeneration (Kowall et al. 1991; Frautschy et al. 1991). However, this effect seems to be dependent on the aggregation state of $A \beta$ as some forms of $A \beta$ do not cause neurodegeneration, whereas the fibrillar form seems to be most neurotoxic (Podlisny et al. 1993; Snow et al. 1994). Interestingly, A $\beta$-mediated axonal toxicity can be rescued by calpain inhibition, which in turn also prevents apoptosis, suggesting a close interplay of amyloidogenic proteins and calcium metabolism (Song et al. 2006).

\section{Axonal transport}

If we assume that axonal degeneration in traumatic or degenerative disease is a mechanistically defined process, then plausibly the disruption of a strategically important entity, such as axonal transport, will ultimately result in malfunction. Because of their enormous length in relation to the cell soma, axons rely on an efficient transport system to target proteins and organelles to specific compartments, such as synaptic terminals or nodes of Ranvier. Deficiencies in axonal transport have been visualized in various models mimicking neurodegenerative disorders, such as motoneuron disease, PD, Alzheimer's dementia, Huntington's disease and Charcot-Marie-Tooth disease (for reviews, see De Vos et al. 2008; Morfini et al. 2009).

Axonal transport is mediated by two major groups of proteins: the kinesins, which mediate anterograde transport, and the dyneins, which are responsible for the retrograde counterpart. Mice expressing the mutant kinesin superfamily member KIF1B $\beta$ show transport defects for synaptic vesicles and progressive muscle weakness attributable to a peripheral neuropathy. In humans, mutations in the KIF1B gene have been found in patients with a hereditary polyneuropathy (Charcot-Marie-Tooth disease, type 2A; Zhao et al. 2001). Transport defects induced by mutations in kinesin light-chain-1 can also activate stress kinases, such as c-Jun-N-terminal kinase (see Kinase activation), and this again can result in abnormal phosphorylation and aggregation of tau (Falzone et al. 2009). Expectedly, retrograde transport defects are no less relevant; missense point mutations in the dynein heavy-chain induce motoneuron degeneration in heterozygous mice and, in homozygous animals, the formation of inclusion bodies has been observed (Hafezparast 2003). Dynein mutations might also be a link to axonal degeneration in motoneuron disease, as a recent study nicely connects axonal transport deficits to autophagic impairment 
and subsequent clearance deficits for aggregated proteins (Ravikumar et al. 2005).

Deficits in axonal transport are also key pathophysiological features in $\mathrm{AD}$ and several publications support the hypothesis that the disturbed axonal transport in $\mathrm{AD}$ is either directly or indirectly caused by $A \beta$ (see also Alzheimer's disease and Aggregation above). For example, accumulations of APP as an indicator of disturbed axonal transport have been found in a subset of axons in TgCRND8/YFP-H mice and alterations in mitochondrial transport have been visualized in TgCRND8/YFP-H/Mito triple transgenics. However, the morphology of the mitochondria suggests rather a partial block than a complete breakdown, which might be correlated with the chronic development of pathology in this model (Adalbert et al. 2009). In another study, intracellular oligomeric $A \beta$ inhibits bidirectional axonal transport via the activation of endogenous casein kinase 2 (Pigino et al. 2009). Application of pharmacological inhibitors of casein kinase 2 is able to prevent the impairment of axonal transport by oligomeric $\mathrm{A} \beta$. The presence of transport deficits has been also demonstrated in vivo, manganese-enhanced magnetic resonance imaging (MRI) being used in the Tg2576 mouse model of $\mathrm{AD}$ to assess axonal transport. In young mice, before $A \beta$ deposition, axonal transport rates have been shown to be normal. After the increase of $A \beta$ deposition in aged mice, however, a significant decrease in axonal transport rates is observed compared with age-matched control animals (Smith et al. 2007). Not only A $\beta$, but also tau seem to play an important role in maintaining axonal transport and axonal integrity. Crossing two mouse mutant strains, one of them overexpressing mutated human APP and the other having a knock-out of tau, results in the extensive formation of axonal spheroids and a degeneration of neurites. This is independent of $A \beta$ plaques indicating a crucial function of tau for the maintenance of axonal integrity (Dawson et al. 2010). Furthermore, a local axonal increase in tau concentration has been shown to promote cargo detachment from microtubules, whereas a decrease allows the uninterrupted transport of cargos (Ebneth et al. 1998; Stamer et al. 2002; Vershinin et al. 2007). In spite of this large body of data, the exact interplay between tau and $A \beta$ in the promotion of axonal degeneration is not yet understood in detail.

Taken together, the data provide strong evidence that axonal transport impairment contributes at least to axonal dystrophy, which can, in the end, culminate in axonal degeneration attributable to deficient cargo exchange. A direct visualization of transport impairment, axonal dystrophy and consecutive degeneration by live-imaging methods should certainly strengthen this hypothesis. The finding that axonal transport is gradually impaired in chronic disease and does not immediately result in axonal degeneration offers an especially challenging possibility for putative therapeutic interventions, as the pathology might still be partially reversible. Nevertheless, a process as complex as axonal transport is unlikely to be rescued by one specific intervention. In terms of pharmacological intervention, factors modulating axonal transport further upstream, such as protein aggregation (Aggregation above), calpain-activation (Calcium-triggered events) and the activation of c-Jun-Nterminal kinase (JNK; Kinase activation) might be more promising targets.

\section{Kinase activation}

Kinases participate in a specific manner in the execution of the axonal destruction program. A few prominent examples shall therefore be discussed in detail here without an attempt to be comprehensive.

The JNKs are known as stress-activated protein kinases because their activities typically increase in response to Various cellular environmental stresses such as osmotic stress, redox stress or irradiation (fro reviews, see Davis 2000; Weston and Davis 2007). Once activated by a stress response or by inflammatory cytokines, they can propagate the signal to induce cellular apoptosis (Kyriakis and Avruch 1996; Ip and Davis 1998). Injury can also activate axonally located JNKs, resulting in axonal transport defects (see Axonal transport) that are associated with the dissociation of heavy-chain kinesin family-5B (KIF5B) protein from tubulin in axons finally leading to increased degeneration (Stagi et al. 2006). For example, activated phospho-JNK has been found to be highly expressed in the lesioned corticospinal tract in a mouse spinal cord injury model and axonal retraction can be inhibited by the application of a pan-JNK inhibitor, which also improves functional recovery (Yoshimura et al. 2011). Vice versa, mutations in the kinesin lightchain-1 are found to result in the activation of JNK, which colocalizes with hyperphosphorylated and accumulated tau in dystrophic axons (Falzone et al. 2009).

As described in detail under Parkinson's disease, axonal degeneration is also one of the earliest pathological hallmarks of PD (Duda et al. 2006). One of the most frequently employed toxin models for PD, the MPTP mouse model, shows only mild to no neuronal loss in the subacute intoxication paradigm. However, the function of dopaminergic neurons, being most dependent on their axonal structures, is significantly impaired (Fox and Brotchie 2010). Here, the JNK pathway is activated via phosphorylated c-Jun in the striatum and in the substantia nigra; this appears not to be correlated with the loss of neuronal cell bodies but might represent a response to damage/loss of axonal terminals (Willesen et al. 2002), as has been corroborated by the finding that c-Jun is activated in dopaminergic neurons from PD patients. The same authors have shown that, in the acute MPTP mouse model of PD, both JNK2 and JNK3, but not 
JNK1, are required for MPTP-induced c-Jun activation and dopaminergic cell demise (Hunot et al. 2004). Different JNK isoforms apparently have distinct functions, since JNK2 and JNK3 seem not to participate in retrograde axonal degeneration following 6-hydroxydopamine (6-OHDA) lesion in mice; although the cell soma is protected in JNK2/3 double-null mutants, the axons still degenerate (Ries et al. 2008).

JNK can also be activated by the dual leucine kinase (DLK) in axonal lesion models in Drosophila and mice. Indeed, animals deficient for DLK show a delay in Wallerian degeneration after sciatic nerve transection and in a toxin model of vincristine treatment (Miller et al. 2009). Activation and phosphorylation of JNK is delayed in WldS explants suggesting that WldS protein expression regulates JNK activation (Barrientos et al. 2011).

Kinases involved in inhibitory myelin signalling are also involved in the regulation of axonal stability. Myelinderived inhibitory molecules, such as Nogo (the neurite outgrowth inhibitor), myelin-associated glycoprotein or oligodendrocyte myelin glycoprotein confer their signal through the trimeric $\mathrm{NgR} / \mathrm{p} 75 / \mathrm{LINGO}-1$ or $\mathrm{NgR} / \mathrm{TROY} /$ LINGO-1 receptor complexes (for a review, see McDonald et al. 2011) or, as has been recently identified, via the paired Ig-like receptor B (Atwal et al. 2008). Downstream, Rhoassociated kinase (ROCK) integrates the signal from other inhibitory receptors, such as ephrin and semaphorin (Goldberg et al. 2004; Goldshmit et al. 2006). Although this signalling pathway has been mostly studied in paradigms of impaired axonal regeneration, indications have been found that this pathway also participates in triggering axonal degeneration. For example, the blocking of Nogo-A signalling is able to attenuate axonal degeneration in an EAE mouse model (Karnezis et al. 2004).

A recent report has implicated the phosphoinositide 4kinase 2 alpha (Pi4k2a) in axonal stability. Knockout mice for Pi4k2a develop a progressive neurological disease with tremor, limb weakness, urinary incontinence and premature mortality. Axonal degeneration in the spinal cord has been found to be a major histological correlate of the symptoms, whereas peripheral nerves appear essentially normal. Thus, Pi4k2a signalling appears to be crucial for axonal integrity and therefore Pi4k2a has been proposed as a candidate gene for hereditary spastic paraplegia (Simons et al. 2009).

\section{Autophagy and the ubiquitin-proteasome system}

Degradation of proteins or even organelles occurs in a homeostatic manner via several degradative routes, one of them being autophagy. Autophagy is a collective term and, in this text, we use it to refer to macroautophagy. Because autophagy is a highly conserved and tightly regulated mechanism any disturbance (be it an increase or a decrease) can result in cellular dysfunction.

Following mechanical axonal damage in a crush model of the optic nerve, an increased number of autophagosomes has been observed in the vicinity of the lesion site and this is dependent on calcium influx. Inhibition of autophagy attenuates axonal degeneration in this model (Koch et al. 2010; Knöferle et al. 2010). Autophagy is also induced in degenerating neurites of sympathetic neurons in an axotomy model, as has been substantiated by an accumulation of autophagosomes and increased expression of LC3-II (a 16$\mathrm{kDa}$ protein that localizes to autophagosomal membranes). Treatment with 3-methyladenine (3-MA) and knockdown of autophagy-regulator $7(\operatorname{Atg} 7)$ or Beclin1 are able to counteract the degenerative process partially (Yang et al. 2007). Cerebellar Purkinje cells show an induction of autophagy in axon terminals upon excitotoxicity, with the process appearing to be axon-specific and independent of the cell body (Yue 2007). This has also been elegantly shown in a green fluorescent protein (GFP)-LC3 transgenic mouse strain crossed with the Lurcher mutant strain, in which a mutant glutamate receptor is constitutively activated and causes Purkinje cell degeneration. Here, GFP-LC3-labelled autophagosomes accumulate in axonal dystrophic swellings (Q. J. Wang et al. 2006). Recently, an in-depth examination of four different mouse models of nigrostriatal axon injury has revealed the presence of ultrastructural features of autophagy, such as autophagic vacuoles, in the degenerating neurites. Autophagic puncta are induced proximally and distally of the mechanical lesion site and in a striatal 6-OHDA injection model (Cheng et al. 2011).

Next to autophagy-mediated degradation, the ubiquitinproteasome system (UPS) has also been shown to be relevant for axonal degeneration. This has been demonstrated by the inhibition of UPS in an optic nerve crush lesion model in which Wallerian degeneration is attenuated by proteasome inhibition. Fragmentation of microtubuli as an early event following crush lesion can be diminished by the application of the proteasome inhibitor MG132 (Zhai et al. 2003). On the other hand, proteasome inhibition by lactacystin causes a dying-back-like degeneration in PC12 cells in vitro (Laser et al. 2003). Thus, a disturbance of proteasome function in one way or another can have detrimental effects, similar to alterations in autophagy.

\section{Therapeutic targets}

Axonal membrane integrity

Structural lesions, such as the disruption of the axonal membrane and microtubule breakage, are the primary events in trauma-induced axonal degeneration and thus could 
represent early therapeutic targets. For example, axolemmal pores, which are thought to be responsible for calcium influx in diffuse axonal injury after brain trauma, can be successfully treated in vitro with Poloxamer 188, a triblock polymer, which is able to reseal membrane pores (Kilinc et al. 2009). The hydrophilic polymer polyethylene glycol (PEG) has similar chemical properties with regard to membrane sealing (Shi and Borgens 2000). The application of PEG-decorated silica nanoparticles in a spinal cord lesion model in vivo results in an accumulation of the particles at the lesion site and the recovery of electrical conduction through the lesion site (Cho et al. 2010). Whether such approaches will be applied in future clinical treatments will largely depend on the feasibility of rapid application following injury, targeted delivery to the lesion site and their sideeffects profile.

Inhibitors of calcium and calcium-dependent enzymes

Calcium influx inhibition, for example by L-type calcium channel blockers such as nifedipine or nimodipine, is highly protective in axonal lesion models in vitro. Metal ions substituting for calcium, such as cobalt and manganese, are also able to attenuate axonal degeneration in this model (George et al. 1995). In the optic nerve crush model in vivo, the application of a mixture of amlodipin, amiloride and NBQX (2,3-dihydroxy-6-nitro-7-sulfamoyl-benzo[f]quinoxaline-2,3-dione) prevents the increase of intra-axonal calcium and consecutive axonal destruction. In reverse, the disintegration of the axon is dramatically increased after the addition of the calcium ionophore A23187 to the lesion site (Knöferle et al. 2010). Inhibition of calcium influx by the Ntype-specific calcium channel blocker omega-conotoxin GVIA is also axonoprotective in a rat model of autoimmune optic neuritis (Gadjanski et al. 2009).

Inhibitors of calpains have been used as a successful strategy to attenuate axonal damage in several models in vitro and in vivo. For example, dorsal root ganglion axons are protected by calpain inhibitors from axotomy-induced axonal degeneration in vitro (George et al. 1995) and from acute axonal degeneration in the spinal cord in vivo (Kerschensteiner et al. 2005). Calpain inhibition has been shown to be protective in models of traumatic brain injury; it successfully prevents axonal beading after shear stress (Kilinc et al. 2009) and is also protective in a model of anoxic axonal damage (Jiang and Stys 2000). After fluid percussion injury, the application of the calpain inhibitor MDL-28170 exhibits protective effects against axonal destruction. As might be expected from the disease mechanism, earlier administration of the drug shows a better axonoprotection than application at a later time point with the best results being achieved when MDL-28170 is administered before lesion (Ai et al. 2007). Interestingly, both studies have demonstrated only partial functional recovery, suggesting that calpain is not the only calcium-dependent downstream target and that other evasive pathways might have been initiated at the same time. Thus, even calpain inhibition may lie too far downstream in terms of functional rescue.

Although the inhibition of calcium influx or intra-axonal calcium release appears to be one of the most potent approaches in the prevention of further degeneration, the kinetics of calcium flux render calcium an unfavourable target for therapeutic interventions in acute lesions. Calcium influx in traumatic lesions usually occurs so fast that a timely intervention appears unrealistic (Knöferle et al. 2010). However, the targeting of calcium could be beneficial in chronic disorders, which have a much slower progression, and this is supported, for example, by the EAE model data. Indeed, riluzole, the only drug licensed for the treatment of ALS, acts as an NMDA receptor antagonist and thus regulates calcium influx to the cell, a possible explanation for its beneficial effects in this motoneuron disorder (Van Damme et al. 2005). Interestingly, recent data from a retrospective Danish population-based study employing logistic regression analysis suggest that subjects prescribed dihydropyridines are less likely to develop PD; this indicates a possible neuroprotective role for these centrally acting L-type calcium channel blockers (Ritz et al. 2010). Evidence is thus accumulating that calcium can also be a target in chronic neurodegenerative disorders, a finding that is of special interest, because many calcium channel blockers have well-known pharmacokinetics in humans and are already widely used in clinical practice.

\section{WldS/NMNAT}

The WldS mutation has been shown to be neuroprotective in several models of chronic degenerative CNS disease such as PD, glaucoma, MS, Charcot-Marie-Tooth disease 1A and axonal dystrophy (Mi et al. 2005; Kaneko et al. 2006; Hasbani and O'Malley 2006; Howell et al. 2007; Wilbrey et al. 2008; Beirowski et al. 2008; Meyer zu Horste et al. 2011). In a recent study evaluating various models of PD, the WldS mutation is protective in anterograde but not retrograde degeneration suggesting that both processes involve different molecular mechanisms (Cheng and Burke 2010).

Further analysis of the biologically effective mechanism of WldS has revealed that the enzymatic activity of NMNAT1 together with the VCP-binding site of UBE4b are required to achieve the full neuroprotective effect comparable to WldS-expression (Avery et al. 2009; Conforti et al. 2009; Yahata et al. 2009). However, in Drosophila, the overexpression of NMNAT3, an isoform of NMNAT that localizes primarily to the cytosol and mitochondria, 
provides axon protection indistinguishable from that of WldS. This shows not only the potential therapeutic value of NMNAT3 in treating degenerative disease, but also the importance of the subcellular localization of the active substrate. Complete loss of NMNAT causes severe axonal degeneration in Drosophila sensory neurons supporting its essential role in the maintenance of axonal and dendritic integrity (Wen et al. 2011). Consistently, axonally targeted NMNAT1 is highly axonoprotective in a mouse model of Wallerian degeneration, although the precise mechanism of action is still under debate (Babetto et al. 2010).

\section{Kinases}

The diversity among kinases is reflected in the plethora of pharmacological kinase inhibitors available. Here, we focus on a few examples, namely inhibitors of ROCK, JNK, GSK3 and IkappaB (IкB), for which particular axonoprotective effects have been described.

Interference with ROCK function has recently been shown to be beneficial in various disease models as it is able to confer neuroprotection and promote axonal regeneration (Lingor et al. 2008; Tönges et al. 2011). However, evidence has also been obtained that ROCK inhibition protects from axonal degeneration. When axons are mechanically severed, they retract because of increased actomyosin contractility. This is based on the regulation of myosin II by myosin light-chain kinase (MLCK), which directly phosphorylates myosin regulatory light chains and activates myosin motor activity. Activated ROCK increases the phosphorylation of myosin regulatory light chains and additionally inhibits myosin light-chain phosphatase by phosphorylation. It possibly even directly phosphorylates the myosin regulatory light chains themselves (Luo 2000). In an in vitro-approach, the application of the pharmacological ROCK inhibitor Y27632 to severed chicken retinal axons has been shown to inhibit myosin light-chain phosphorylation and thereby significantly decreases the axonal retraction distance (Gallo 2004).

In a mouse model of EAE, both the parenteral and oral administration of the ROCK inhibitor fasudil prevents the development of EAE induced by proteolipid protein. In addition to a reduction of the specific proliferation of lymphocytes, a downregulation of interleukin (IL)-17 and a marked decrease of the interferon-gamma/IL-4 ratio, CNS demyelination and acute axonal transections are robustly attenuated (Sun et al. 2006). This protection from axonal degeneration has been confirmed by a study in a rat model of experimental autoimmune neuritis (EAN)in which ROCK inhibition can even reduce EAN severity when administered after disease onset. Again, inflammatory cell infiltration is markedly decreased and the secretion of inflammatory cytokines is reduced (Pineda et al. 2011).
The mechanisms of action of ROCK inhibition with regard to the attenuation of axonal degeneration thus seem to be manifold and at least partially mediated via the modulation of inflammatory processes and interference with cytoskeleton motility.

JNKs have been proposed as therapeutic targets for several neurodegenerative disorders. However, in addition to their neuroprotective action, experimental evidence now suggests that JNK inhibition protects degenerating axons. For example, the application of SP600125, a pan-JNK inhibitor, attenuates axonal retraction after spinal cord lesion and improves the motor outcome (Yoshimura et al. 2011). A shortcoming of JNK inhibition as a therapeutic approach might be the broad range of JNK-mediated effects, which result from the association of JNKs with other proteins in a variety of signalosomes. Here, a selective targeting of JNKs will not be sufficient but will require peptides that block molecular domains of such JNK signalling complexes (Waetzig and Herdegen 2005).

Finally, in a recent large scale screen of 480 bioactive compounds, inhibitors of GSK-3 and IKB kinase have been found to delay the fragmentation of severed axons markedly in vitro. This has been verified by short-hairpin- RNAmediated knock-down of these target genes (Gerdts et al. 2011). Although this data has to be verified in vivo, these kinases might represent novel pharmacological targets in axonal degeneration.

From a therapeutic perspective, kinase inhibitors are promising substances and several drugs have already been licensed for human use, mostly in the field of anti-cancer therapy. Because kinase inhibitors are usually not completely specific, target selectivity will be a major criterion in the selection process when it comes to therapeutic considerations.

\section{Autophagy}

The therapeutic range of pharmacological approaches regulating autophagy appears to be narrow because a basal level of autophagy is essential for all cells, whereas slight shifts of this equilibrium in either direction might cause pathology (for excellent reviews, see Chu et al. 2009; Jaeger and Wyss-Coray 2009).

For acute axonal degeneration in the rat optic nerve in vivo, we have been able to show a clear axon stabilizing effect of autophagy inhibition with 3-MA, suggesting that autophagy inhibition in the early phase after a traumatic nerve injury might be beneficial (Knöferle et al. 2010). This protective effect on neurite integrity has also been found by several other groups in other in vitro models: the inhibition of autophagy by small molecules or siRNA results in attenuated neurite degeneration and increases cell viability in a growth-factor-deprivation model in mouse superior cervical ganglion neurons (Yang et al. 2007). In agreement, Atg7 
knockdown also partially protects neurites from degeneration in the first $12 \mathrm{~h}$ following axonal transection in the same cell culture model. Similarly, autophagy inhibition in Atg7 knock-out mice results in protection from neuron death and axonal degeneration in a hypoxic-ischaemic injury model (Koike et al. 2008).

On the other hand, autophagy seems to be neuroprotective under certain conditions depending on the phase and form of axonal degeneration. For instance, in an in vivo model of mouse traumatic brain injury, treatment with the autophagy-inducing drug rapamycin significantly improves functional recovery (Erlich et al. 2007) and similar results have been obtained by other groups in related paradigms (Egami et al. 2005; Sadasivan et al. 2008).

In chronic neurodegenerative disease models, therapeutic modulation of autophagy in either direction has been shown to be beneficial according to the specific model. For example, activation of autophagy by the mTOR (mammalian target of rapamycin) inhibitor rapamycin attenuates the accumulation of mutant huntingtin and is neuroprotective in a Drosophila model of Huntington's disease (Ravikumar et al. 2004). Conversely, application of the autophagy inhibitor 3-MA or knock-down of autophagy-regulators Atg5 or Atg12 is neuroprotective in the $\mathrm{MPP}^{+}$and alpha-synuclein (A53T) cell culture models of PD (Wong et al. 2011).

The regulation of autophagy in a therapeutic manner will largely depend on increasing knowledge of the regulation of this pathway in specific pathologies. Part of this improved understanding must be a more detailed temporal resolution. Autophagic flux might be increased at one point after lesion but may return to normal levels or be inhibited at another. A unidirectional approach, which does not take into account the kinetics of autophagic activity, might therefore result in unwanted detrimental effects by interference with this conserved physiological mechanism.

\section{Aggregation}

The search for effective compounds or strategies to prevent protein aggregation is one of the hottest topics in current neurodegeneration research. Because of primary axonal damage in the course of aggregopathies, this approach holds the promise of achieving true neuroprotective and possibly neurorestorative effects. One therapeutic approach that has been tested extensively in AD mouse models is the immunization of animals with antibodies against $\mathrm{A} \beta$. In an APP mutant mouse model (APPswe/PS1dE9), the application of an anti-A $\beta$ antibody has not only resulted in a modest reduction of $\mathrm{A} \beta$ in the brain, but can also significantly attenuate axonal degeneration resulting in higher axon densities in the cortex and hippocampus of the treated mutant mice (Liu et al. 2011). Targeting the aggregation of tau seems similarly promising. Tau is a microtubule-associated protein and both the loss and the toxic gain of function plus the hyperphosphorylation and aggregation of tau have been prime examples for aggregation-related axonal dystrophy and degeneration, for example in AD. Oligomeric forms of tau have been shown to impair fast axonal transport in vitro. This effect can be attenuated by the addition of heat shock protein 70 to oligomeric and fibrillar tau (Patterson et al. 2011). The use of drugs previously tested in human trials and licensed for other pharmacological purposes is especially auspicious. In this context, immunophilin ligands such as FK506 (an immunosuppressant that has been in clinical use for more than 15 years) have recently showed remarkable effects. FK506-binding protein (FKBP) family members have previously been demonstrated to accelerate the aggregation of alpha-synuclein in vitro. In a cell culture model of synucleinopathy, FK506 has been shown to inhibit alphasynuclein aggregation and neuronal cell death. Similarly, aggregate formation is reduced and cell viability is improved after oral administration of FK506 in an AAVbased mouse model of PD in vivo (Gerard et al. 2010). Nevertheless, approaches involving interference with aggregation will have to be carefully tuned in order to avoid converse effects. An increase of toxic oligomeric species at the cost of less fibril formation might result in exactly the opposite outcome from that desired, as has been shown for the disaccharide trehalose; although $\mathrm{A} \beta 40$ aggregation can be inhibited by trehalose, the same treatment prevents only the formation of fibrillar forms of $A \beta 42$, toxic oligomeres being still present and the toxicity of $A \beta 42$ not being attenuated (Liu et al. 2005).

\section{Growth factors}

Trophic factors exert an influence on growth, differentiation and survival of neuronal populations during development and in the adult. Because of their pleiotrophic effects, they have not only been suggested as therapeutic agents for a number of neurological disorders, but have already been tested in human trials (e.g. Gill et al. 2003). Here, we will review only a few prominent examples that have shown protective effects in terms of axonal degeneration.

Viral vector-mediated overexpression of the neurotrophic factor glial-cell-line derived neurotrophic factor (GDNF) in the substantia nigra is able to improve axonal stability and somatic survival of dopaminergic neurons in the 6-OHDA model of PD. Thus, 6-OHDA-mediated axonal dying-back pathology can be rescued, at least partially, by GDNF (Mandel 1997). Kirik et al. (2000) have shown that GDNF application to the striatum is required in this model in order to protect the projecting nigrostriatal fibres. Thus, the location of growth factor application needs to be considered from a technical point of view. On the other hand, GDNF is not sufficiently protective in a model of alpha-synuclein- 
induced axonal degeneration and dopaminergic terminals are equally unprotected by lentiviral GDNF expression. Corresponding to this finding, the expression of GDNF also does not prevent the aggregation of alpha-synuclein in dopaminergic terminals (Decressac et al. 2011). Lentiviral vector application of GDNF is furthermore not protective against axonal degeneration induced by the overexpression of the human pathogenically mutated A30P alpha-synuclein (Lo Bianco et al. 2004). All this makes clear that a growth factor such as GDNF acts only on parts of the degenerative cascade and a therapeutic effect in humans will be limited if major pathomechanisms, such as aggregation, are not sufficiently addressed. Axonal transport deficits might also be responsible for the limited effect of growth factor therapy in human PD patients, because the trophic factors are not sufficiently transported to the cell soma. For example, striatal delivery of AAV-neurturin will require much longer retrograde transport in humans than in experimental models involving smaller mammals, i.e. non-human primates or rodents (Bartus et al. 2011).

In an axotomy model, local application of ciliary neurotrophic factor is able to prevent the degeneration of rat facial motoneurons (Sendtner et al. 1990) and a more recent report presents data on ciliary neurotrophic factor (CNTF)-mediated protection in axonal pruning of motoneurons in the SOD1 (G93A) mouse model (Pun et al. 2006). Here, the stalling of synaptic vesicles has been identified as an early sign of axonal dysfunction and the application of CNTF is able to reverse this pathology, whereas GDNF does not. Axonal die-back induced by axotomy of the optic nerve can be inhibited by the local application of brain-derived neurotrophic factor and also by neurotrophin-3 and CNTF (Weibel et al. 1995).

Erythropoietin (EPO) is a multifunctional cytokine that not only controls erythropoiesis, but has also been attributed neuroprotective properties (e.g. Grunfeld et al. 2007; Xue et al. 2010; Reitmeir et al. 2011). Several studies in a model of peripheral neuropathy (acrylamide-mediated axonal injury) have demonstrated that EPO is the functional mediator of NO-induced axonal protection and can be released by Schwann cells upon injury. EPO signalling in this model is dependent on the activation of hypoxia-inducible factor- $1 \alpha$ (Keswani et al. 2004, 2011).

\section{Concluding remarks}

The molecular machinery of axonal degeneration still requires a much better understanding and this can be partially achieved through in vivo visualization of the implicated processes. Here, life-imaging techniques (Misgeld and Kerschensteiner 2006) and MRI methods (Ge 2006; Fox et al. 2011; Kim et al. 2011) might yield more information and further insights can be expected from the evolution of these methods
(Westphal et al. 2008). Because of the multitude of aetiologies and molecular mechanisms involved in axonal degeneration, therapeutic approaches aimed at prevention or restitution will probably require multiple strategies. Intriguingly, in spite of the pathological diversity of axonal degeneration, some keystones of the degenerative cascade and thus some key targets appear to be identical. The regulation of axonal calcium levels, for example, is of major importance for acute and chronic degenerative paradigms. On the other hand, the kinetics of intra-axonal calcium levels represents a challenge when it comes to a therapeutic application. Alterations of homeostatic mechanisms, such as autophagy, are equally efficient in modulating axonal stability but therapeutic intervention appears to depend on a narrow time window, outside of which any interference with such essential cellular processes might lead to detrimental instead of beneficial effects. Questions of administration routes, tissue specific targeting, timing and duration are not discussed in this review but will have to be considered with respect to the design of axonoprotective therapies.

Acknowledgement We are indebted to Cathy Ludwig for her help in proofreading the manuscript as a native speaker.

Open Access This article is distributed under the terms of the Creative Commons Attribution License which permits any use, distribution, and reproduction in any medium, provided the original author(s) and the source are credited.

\section{References}

Adalbert R, Nógrádi A, Szabó A, Coleman MP (2006) The slow Wallerian degeneration gene in vivo protects motor axons but not their cell bodies after avulsion and neonatal axotomy. Eur J Neurosci 24:2163-2168

Adalbert R, Nogradi A, Babetto E, Janeckova L, Walker SA, Kerschensteiner M, Misgeld T, Coleman MP (2009) Severely dystrophic axons at amyloid plaques remain continuous and connected to viable cell bodies. Brain 132:402-416

Ai J, Liu E, Wang J, Chen Y, Yu J, Baker AJ (2007) Calpain inhibitor MDL-28170 reduces the functional and structural deterioration of corpus callosum following fluid percussion injury. J Neurotrauma 24:960-978

Alim MA, Hossain MS, Arima K, Takeda K, Izumiyama Y, Nakamura M, Kaji H, Shinoda T, Hisanaga S, Ueda K (2002) Tubulin seeds alpha-synuclein fibril formation. J Biol Chem 277:2112-2117

Alix JJP, Dolphin AC, Fern R (2008) Vesicular apparatus, including functional calcium channels, are present in developing rodent optic nerve axons and are required for normal node of Ranvier formation. J Physiol 586:4069-4089

Atwal JK, Pinkston-Gosse J, Syken J, Stawicki S, Wu Y, Shatz C, Tessier-Lavigne $\mathrm{M}$ (2008) PirB is a functional receptor for myelin inhibitors of axonal regeneration. Science 322:967-970

Avery MA, Sheehan AE, Kerr KS, Wang J, Freeman MR (2009) Wld S requires Nmnat1 enzymatic activity and N16-VCP interactions to suppress Wallerian degeneration. J Cell Biol 184:501-13

Babetto E, Beirowski B, Janeckova L, Brown R, Gilley J, Thomson D, Ribchester RR, Coleman MP (2010) Targeting NMNAT1 to 
axons and synapses transforms its neuroprotective potency in vivo. J Neurosci 30:13291-13304

Barrientos S, Martinez NW, Yoo S, Jara JS, Zamorano S, Hetz C, Twiss JL, Alvarez J, Court F (2011) Axonal degeneration is mediated by the mitochondrial permeability transition pore. J Neurosci 31:966-978

Bartus RT, Herzog CD, Chu Y, Wilson A, Brown L, Siffert J, Johnson EM, Olanow CW, Mufson EJ, Kordower JH (2011) Bioactivity of AAV2-neurturin gene therapy (CERE-120): differences between Parkinson's disease and nonhuman primate brains. Mov Disord 26:27-36

Beirowski B, Adalbert R, Wagner D, Grumme DS, Addicks K, Ribchester RR, Coleman MP (2005) The progressive nature of Wallerian degeneration in wild-type and slow Wallerian degeneration (WldS) nerves. BMC Neurosci 6:6

Beirowski B, Babetto E, Coleman MP, Martin KR (2008) The WldS gene delays axonal but not somatic degeneration in a rat glaucoma model. Eur J Neurosci 28:1166-1179

Beirowski B, Babetto E, Gilley J, Mazzola F, Conforti L, Janeckova L, Magni G, Ribchester RR, Coleman MP (2009) Non-nuclear Wld (S) determines its neuroprotective efficacy for axons and synapses in vivo. J Neurosci 29:653-668

Bennett GJ, Liu GK, Xiao WH, Jin HW, Siau C (2011) Terminal arbor degeneration-a novel lesion produced by the antineoplastic agent paclitaxel. Eur J Neurosci 33:1667-1676

Berger F, Lau C, Dahlmann M, Ziegler M (2005) Subcellular compartmentation and differential catalytic properties of the three human nicotinamide mononucleotide adenylyltransferase isoforms. J Biol Chem 280:36334-36341

Bertrand E, Lechowicz W, Lewandowska E, Szpak GM, Dymecki J, Kosno-Kruszewska E, Wierzba-Bobrowicz T (2003) Degenerative axonal changes in the hippocampus and amygdala in Parkinson's disease. Folia Neuropathol 41:197-207

Bilsland LG, Sahai E, Kelly G, Golding M, Greensmith L, Schiavo G (2010) Deficits in axonal transport precede ALS symptoms in vivo. Proc Natl Acad Sci USA 107:20523-20528

Boutajangout A, Authelet M, Blanchard V, Touchet N, Tremp G, Pradier L, Brion J-P (2004) Characterisation of cytoskeletal abnormalities in mice transgenic for wild-type human tau and familial Alzheimer's disease mutants of APP and presenilin-1. Neurobiol Dis 15:47-60

Braak H, Tredici KD, Vos RAID, Steur ENHJ, Braak E (2003) Staging of brain pathology related to sporadic Parkinson's disease. Neurobiol Aging 24:197-211

Bramlett HM, Dietrich WD (2007) Progressive damage after brain and spinal cord injury: pathomechanisms and treatment strategies. Prog Brain Res 161:125-141

Burke RE (2010) Intracellular signalling pathways in dopamine cell death and axonal degeneration. Prog Brain Res 183:79-97

Calkins MJ, Reddy PH (2011) Amyloid beta impairs mitochondrial anterograde transport and degenerates synapses in Alzheimer's disease neurons. Biochim Biophys Acta 1812:507-513

Cavanagh JB (1964) The significance of the "dying back" process in experimental and human neurological disease. Int Rev Exp Pathol 3:219-267

Cavanagh JB (1979) The "dying back" process. A common denominator in many naturally occurring and toxic neuropathies. Arch Pathol Lab Med 103:659-664

Chang DTW, Honick AS, Reynolds IJ (2006) Mitochondrial trafficking to synapses in cultured primary cortical neurons. J Neurosci 26:7035-7045

Cheng H-C, Burke RE (2010) The Wld(S) mutation delays anterograde, but not retrograde, axonal degeneration of the dopaminergic nigro-striatal pathway in vivo. J Neurochem 113:683-691

Cheng H-C, Kim SR, Oo TF, Kareva T, Yarygina O, Rzhetskaya M, Wang C, During M, Talloczy Z, Tanaka K, Komatsu M,
Kobayashi K, Okano H, Kholodilov N, Burke RE (2011) Akt suppresses retrograde degeneration of dopaminergic axons by inhibition of macroautophagy. J Neurosci 31:2125-2135

Cho Y, Shi R, Ivanisevic A, Borgens RB (2010) Functional silica nanoparticle-mediated neuronal membrane sealing following traumatic spinal cord injury. J Neurosci Res 88:1433-1444

Chu CT, Plowey ED, Dagda RK, Hickey RW, Cherra SJ, Clark RSB (2009) Autophagy in neurite injury and neurodegeneration: in vitro and in vivo models. Methods Enzymol 453:217-249

Chung CY, Koprich JB, Siddiqi H, Isacson O (2009) Dynamic changes in presynaptic and axonal transport proteins combined with striatal neuroinflammation precede dopaminergic neuronal loss in a rat model of AAV alpha-synucleinopathy. J Neurosci 29:3365-33673

Conforti L, Wilbrey A, Morreale G, Janeckova L, Beirowski B, Adalbert R, Mazzola F, Di Stefano M, Hartley R, Babetto E, Smith T, Gilley J, Billington RA, Genazzani AA, Ribchester RR, Magni G, Coleman M (2009) Wld S protein requires Nmnat activity and a short $\mathrm{N}$-terminal sequence to protect axons in mice. J Cell Biol 184:491-500

Davis RJ (2000) Signal transduction by the JNK group of MAP kinases. Cell 103:239-252

Dawson HN, Cantillana V, Jansen M, Wang H, Vitek MP, Wilcock DM, Lynch JR, Laskowitz DT (2010) Loss of tau elicits axonal degeneration in a mouse model of Alzheimer's disease. Neuroscience 169:516-531

De Vos KJ, Grierson AJ, Ackerley S, Miller CCJ (2008) Role of axonal transport in neurodegenerative diseases. Annu Rev Neurosci 31:151-173

Deckwerth TL, Johnson EM (1994) Neurites can remain viable after destruction of the neuronal soma by programmed cell death (apoptosis). Dev Biol 165:63-72

Decressac M, Ulusoy A, Mattsson B, Georgievska B, Romero-Ramos M, Kirik D, Björklund A (2011) GDNF fails to exert neuroprotection in a rat $\{$ alpha\}-synuclein model of Parkinson's disease. Brain 134:2302-2311

Dickson TC, King CE, McCormack GH, Vickers JC (1999) Neurochemical diversity of dystrophic neurites in the early and late stages of Alzheimer's disease. Exp Neurol 156:100-110

Duda JE, Giasson BI, Lee VM-Y, Trojanowski JQ (2006) Is the initial insult in Parkinson's disease and dementia with Lewy bodies a neuritic dystrophy? Ann N Y Acad Sci 991:295-297

Dziedzic T, Metz I, Dallenga T, König FB, Müller S, Stadelmann C, Brück W (2010) Wallerian degeneration: a major component of early axonal pathology in multiple sclerosis. Brain Pathol 20:976985

Ebneth A, Godemann R, Stamer K, Illenberger S, Trinczek B, Mandelkow E (1998) Overexpression of tau protein inhibits kinesindependent trafficking of vesicles, mitochondria, and endoplasmic reticulum: implications for Alzheimer's disease. J Cell Biol 143:777-794

Egami Y, Kiryu-Seo S, Yoshimori T, Kiyama H (2005) Induced expressions of Rab24 GTPase and LC3 in nerve-injured motor neurons. Biochem Biophys Res Commun 337:1206-1213

Emre M, Geula C, Ransil BJ, Mesulam MM (1992) The acute neurotoxicity and effects upon cholinergic axons of intracerebrally injected beta-amyloid in the rat brain. Neurobiol Aging 13:553559

Erlich S, Alexandrovich A, Shohami E, Pinkas-Kramarski R (2007) Rapamycin is a neuroprotective treatment for traumatic brain injury. Neurobiol Dis 26:86-93

Falzone TL, Stokin GB, Lillo C, Rodrigues EM, Westerman EL, Williams DS, Goldstein LSB (2009) Axonal stress kinase activation and tau misbehavior induced by kinesin-1 transport defects. J Neurosci 29:5758-5767

Ferguson B, Matyszak MK, Esiri MM, Perry VH (1997) Axonal damage in acute multiple sclerosis lesions. Brain 120:393-399 
Fern R, Ransom BR, Waxman SG (1995) Voltage-gated calcium channels in CNS white matter: role in anoxic injury. J Neurophysiol 74:369-377

Fischer LR, Glass JD (2007) Axonal degeneration in motor neuron disease. Neurodegener Dis 4:431-442

Fischer LR, Culver DG, Tennant P, Davis AA, Wang M, CastellanoSanchez A, Khan J, Polak MA, Glass JD (2004) Amyotrophic lateral sclerosis is a distal axonopathy: evidence in mice and man. Exp Neurol 185:232-240

Fox SH, Brotchie JM (2010) The MPTP-lesioned non-human primate models of Parkinson's disease. Past, present, and future. Prog Brain Res 184:133-157

Fox RJ, Cronin T, Lin J, Wang X, Sakaie K, Ontaneda D, Mahmoud SY, Lowe MJ, Phillips MD (2011) Measuring myelin repair and axonal loss with diffusion tensor imaging. Am J Neuroradiol 32:85-91

Frautschy SA, Baird A, Cole GM (1991) Effects of injected Alzheimer betaamyloid cores in rat brain. Proc Natl Acad Sci USA 88:8362-8366

Gadjanski I, Boretius S, Williams SK, Lingor P, Knöferle J, Sättler MB, Fairless R, Hochmeister S, Süss KW, Michaelis T, Frahm J, Storch MK, Bähr M, Diem R (2009) Role of N-Type voltagedependent calcium channels in autoimmune optic neuritis. Ann Neurol 66:81-93

Gallo G (2004) Myosin II activity is required for severing-induced axon retraction in vitro. Exp Neurol 189:112-121

Ge Y (2006) Seeing is believing: in vivo evolution of multiple sclerosis pathology with magnetic resonance. Top Magn Reson Imaging 17:295-306

George EB, Glass JD, Griffin JW (1995) Axotomy-induced axonal degeneration influx through ion-specific channels. J Neurosci 75:6445-6452

Gerard M, Deleersnijder A, Daniëls V, Schreurs S, Munck S, Reumers V, Pottel H, Engelborghs Y, Van den Haute C, Taymans J-M, Debyser Z, Baekelandt V (2010) Inhibition of FK506 binding proteins reduces alpha-synuclein aggregation and Parkinson's disease-like pathology. J Neurosci 30:2454-2463

Gerdts J, Sasaki Y, Vohra B, Marasa J, Milbrandt J (2011) Image-based screening identifies novel roles for IKK and GSK3 in axonal degeneration. J Biol Chem 286:28011-28018

Gill SS, Patel NK, Hotton GR, O Sullivan K, McCarter R, Bunnage M, Brooks DJ, Svendsen CN, Heywood P (2003) Direct brain infusion of glial cell line-derived neurotrophic factor in Parkinson disease. Nat Med 9:589-595

Gilley J, Coleman MP (2010) Endogenous Nmnat2 is an essential survival factor for maintenance of healthy axons.PLoS Biol 8: e1000300

Glass JD, Brushart TM, George EB, Griffin JW (1993) Prolonged survival of transected nerve fibres in C57BL/Ola mice is an intrinsic characteristic of the axon. J Neurocytol 22:311-321

Goldberg JL, Vargas ME, Wang JT, Mandemakers W, Oster SF, Sretavan DW, Barres B (2004) An oligodendrocyte lineage-specific semaphorin, Sema5A, inhibits axon growth by retinal ganglion cells. J Neurosci 24:4989-4999

Goldshmit Y, McLenachan S, Turnley A (2006) Roles of Eph receptors and ephrins in the normal and damaged adult CNS. Brain Res Rev 52:327-345

Gould TW, Buss RR, Vinsant S, Prevette D, Sun W, Knudson CM, Milligan CE, Oppenheim RW (2006) Complete dissociation of motor neuron death from motor dysfunction by Bax deletion in a mouse model of ALS. J Neurosci 26:8774-8786

Grunfeld JF, Barhum Y, Blondheim N, Rabey J-M, Melamed E, Offen D (2007) Erythropoietin delays disease onset in an amyotrophic lateral sclerosis model. Exp Neurol 204:260-263

Gurney ME, Pu H, Chiu AY, Dal Canto MC, Polchow CY, Alexander DD, Caliendo J, Hentati A, Kwon YW, Deng HX (1994) Motor neuron degeneration in mice that express a human $\mathrm{Cu}, \mathrm{Zn}$ superoxide dismutase mutation. Science 264:1772-1775
Hafezparast M (2003) Mutations in dynein link motor neuron degeneration to defects in retrograde transport. Science 300:808-812

Hasbani DM, O'Malley KL (2006) Wld(S) mice are protected against the Parkinsonian mimetic MPTP. Exp Neurol 202:93-99

Hatakeyama S, Yada M, Matsumoto M, Ishida N, Nakayama KI (2001) $\mathrm{U}$ box proteins as a new family of ubiquitin-protein ligases.J Biol Chem 276:33111-33120

Hirano A (1996) Neuropathology of ALS: an overview. Neurology 47: S63-S66

Hoopfer ED, McLaughlin T, Watts RJ, Schuldiner O, O'Leary DDM, Luo L (2006) Wlds protection distinguishes axon degeneration following injury from naturally occurring developmental pruning. Neuron 50:883-895

Howell GR, Libby RT, Jakobs TC, Smith RS, Phalan FC, Barter JW, Barbay JM, Marchant JK, Mahesh N, Porciatti V, Whitmore AV, Masland RH, John SWM (2007) Axons of retinal ganglion cells are insulted in the optic nerve early in DBA/2 J glaucoma. J Cell Biol 179:1523-1537

Huang J, Friedland RP, Auchus AP (2007) Diffusion tensor imaging of normal-appearing white matter in mild cognitive impairment and early Alzheimer disease: preliminary evidence of axonal degeneration in the temporal lobe. Am J Neuroradiol 28:1943-1948

Hunot S, Vila M, Teismann P, Davis RJ, Hirsch EC, Przedborski S, Rakic P, Flavell RA (2004) JNK-mediated induction of cyclooxygenase 2 is required for neurodegeneration in a mouse model of Parkinson's disease. Proc Natl Acad Sci USA 101:665-670

Ip YT, Davis RJ (1998) Signal transduction by the c-Jun N-terminal kinase (JNK)-from inflammation to development. Curr Opin Cell Biol 10:205-219

Iseki E, Marui W, Kosaka K, Akiyama H, Ueda K, Iwatsubo T (1998) Degenerative terminals of the perforant pathway are human alphasynuclein-immunoreactive in the hippocampus of patients with diffuse Lewy body disease. Neurosci Lett 258:81-84

Jaeger PA, Wyss-Coray T (2009) All-you-can-eat: autophagy in neurodegeneration and neuroprotection. Mol Neurodegener 4:16

Jawhar S, Trawicka A, Jenneckens C, Bayer TA, Wirths O (2010) Motor deficits, neuron loss, and reduced anxiety coinciding with axonal degeneration and intraneuronal Abeta aggregation in the 5XFAD mouse model of Alzheimer's disease. Neurobiol Aging 33(1):e29-40

Jensen PH, Hager H, Nielsen MS, Hojrup P, Gliemann J, Jakes R (1999) Alpha-synuclein binds to Tau and stimulates the protein kinase A-catalyzed tau phosphorylation of serine residues 262 and 356. J Biol Chem 274:25481-25489

Jiang Q, Stys PK (2000) Calpain inhibitors confer biochemical, but not electrophysiological, protection against anoxia in rat optic nerves. J Neurochem 74:2101-2107

Kampfl A, Posmantur R, Nixon R, Grynspan F, Zhao X, Liu SJ, Newcomb JK, Clifton GL, Hayes RL (1996) Mu-calpain activation and calpain-mediated cytoskeletal proteolysis following traumatic brain injury. J Neurochem 67:1575-1583

Kanazawa T, Uchihara T, Takahashi A, Nakamura A, Orimo S, Mizusawa H (2008) Three-layered structure shared between Lewy bodies and Lewy neurites - three-dimensional reconstruction of triple-labeled sections. Brain Pathol 18:415-422

Kaneko S, Wang J, Kaneko M, Yiu G, Hurrell JM, Chitnis T, Khoury SJ, He Z (2006) Protecting axonal degeneration by increasing nicotinamide adenine dinucleotide levels in experimental autoimmune encephalomyelitis models. J Neurosci 26:9794-9804

Karnezis T, Mandemakers W, McQualter JL, Zheng B, Ho PP, Jordan KA, Murray BM, Barres B, Tessier-Lavigne M, Bernard CCA (2004) The neurite outgrowth inhibitor Nogo A is involved in autoimmune-mediated demyelination. Nat Neurosci 7:736-744

Kerschensteiner M, Schwab ME, Lichtman JW, Misgeld T (2005) In vivo imaging of axonal degeneration and regeneration in the injured spinal cord. Nat Med 11:572-577 
Keswani SC, Buldanlioglu U, Fischer A, Reed N, Polley M, Liang H, Zhou C, Jack C, Leitz GJ, Hoke A (2004) A novel endogenous erythropoietin mediated pathway prevents axonal degeneration. Ann Neurol 56:815-826

Keswani SC, Bosch-Marcé M, Reed N, Fischer A, Semenza GL, Höke A (2011) Nitric oxide prevents axonal degeneration by inducing HIF-1-dependent expression of erythropoietin. Proc Natl Acad Sci USA 108:4986-4990

Kilinc D, Gallo G, Barbee K (2009) Mechanical membrane injury induces axonal beading through localized activation of calpain. Exp Neurol 219:553-561

Kim JH, Wu T-H, Budde MD, Lee J-M, Song S-K (2011) Noninvasive detection of brainstem and spinal cord axonal degeneration in an amyotrophic lateral sclerosis mouse model. NMR Biomed 24:163-169

Kim-Han JS, Antenor-Dorsey JA, O’Malley KL (2011) The Parkinsonian mimetic, MPP+, specifically impairs mitochondrial transport in dopamine axons. J Neurosci 31:7212-7221

King AE, Dickson TC, Blizzard CA, Woodhouse A, Foster SS, Chung RS, Vickers JC (2011) Neuron-glia interactions underlie ALS-like axonal cytoskeletal pathology. Neurobiol Aging 32:459-469

Kirik D, Rosenblad C, Björklund A (2000) Preservation of a functional nigrostriatal dopamine pathway by GDNF in the intrastriatal 6OHDA lesion model depends on the site of administration of the trophic factor. Eur J Neurosci 12:3871-3882

Kish SJ, Shannak K, Hornykiewicz O (1988) Uneven pattern of dopamine loss in the striatum of patients with idiopathic Parkinson's disease. Pathophysiologic and clinical implications. N Engl J Med 318:876-880

Knöferle J, Koch JC, Ostendorf T, Michel U, Planchamp V, Vutova P, Tönges L, Stadelmann C, Brück W, Bähr M, Lingor P (2010) Mechanisms of acute axonal degeneration in the optic nerve in vivo. Proc Natl Acad Sci USA 107:6064-6069

Koch JC, Knöferle J, Tönges L, Ostendorf T, Bähr M, Lingor P (2010) Acute axonal degeneration in vivo is attenuated by inhibition of autophagy in a calcium-dependent manner. Autophagy (in press)

Koike M, Shibata M, Tadakoshi M, Gotoh K, Komatsu M, Waguri S, Kawahara N, Kuida K, Nagata S, Kominami E, Tanaka K, Uchiyama Y (2008) Inhibition of autophagy prevents hippocampal pyramidal neuron death after hypoxic-ischemic injury. Am J Pathol 172:454-469

Kowall NW, Beal MF, Busciglio J, Duffy LK, Yankner BA (1991) An in vivo model for the neurodegenerative effects of beta amyloid and protection by substance P. Proc Natl Acad Sci USA 88:7247-7251

Kurnellas MP, Nicot A, Shull GE, Elkabes S (2005) Plasma membrane calcium ATPase deficiency causes neuronal pathology in the spinal cord: a potential mechanism for neurodegeneration in multiple sclerosis and spinal cord injury. FASEB J 19:298-300

Kyriakis JM, Avruch J (1996) Sounding the alarm: protein kinase cascades activated by stress and inflammation. J Biol Chem 271:24313-24316

Lach B, Grimes D, Benoit B, Minkiewicz-Janda A (1992) Caudate nucleus pathology in Parkinson's disease: ultrastructural and biochemical findings in biopsy material. Acta Neuropathol 83:352360

Laser H, Mack TGA, Wagner D, Coleman MP (2003) Proteasome inhibition arrests neurite outgrowth and causes "dying-back" degeneration in primary culture. J Neurosci Res 74:906-916

Li H, Li SH, Yu ZX, Shelbourne P, Li XJ (2001) Huntingtin aggregateassociated axonal degeneration is an early pathological event in Huntington's disease mice. J Neurosci 21:8473-81

Li Y, Liu W, Oo TF, Wang L, Tang Y, Jackson-Lewis V, Zhou C, Geghman K, Bogdanov M, Przedborski S, Beal MF, Burke RE, Li C (2009) Mutant LRRK2(R1441G) BAC transgenic mice recapitulate cardinal features of Parkinson's disease. Nat Neurosci $12: 826-828$
Lin C-H, Tsai P-I, Wu R-M, Chien C-T (2010) LRRK2 G2019S mutation induces dendrite degeneration through mislocalization and phosphorylation of tau by recruiting autoactivated GSK $3 \beta$. J Neurosci 30:13138-13149

Lingor P, Tönges L, Pieper N, Bermel C, Barski E, Planchamp V, Bähr $M$ (2008) ROCK inhibition and CNTF interact on intrinsic signalling pathways and differentially regulate survival and regeneration in retinal ganglion cells. Brain 131:250-263

Liu R, Barkhordarian H, Emadi S, Park CB, Sierks MR (2005) Trehalose differentially inhibits aggregation and neurotoxicity of betaamyloid 40 and 42. Neurobiol Dis 20:74-81

Liu Y, Lee MK, James MM, Price DL, Borchelt DR, Troncoso JC, Oh ES (2011) Passive (amyloid- $\beta$ ) immunotherapy attenuates monoaminergic axonal degeneration in the A $\beta$ PPswe/PS1dE9 mice. J Alzheimer Dis 23:271-279

Lo Bianco C, Déglon N, Pralong W, Aebischer P (2004) Lentiviral nigral delivery of GDNF does not prevent neurodegeneration in a genetic rat model of Parkinson's disease. Neurobiol Dis 17:283-289

Lunn ER, Perry VH, Brown MC, Rosen H, Gordon S (1989) Absence of Wallerian degeneration does not hinder regeneration in peripheral nerve. Eur J Neurosci 1:27-33

Luo L (2000) Rho GTPases in neuronal morphogenesis. Nat Rev Neurosci 1:173-180

Luo L, O'Leary DD (2005) Axon retraction and degeneration in development and disease. Annu Rev Neurosci 28:127-156

MacDonald JM, Beach MG, Porpiglia E, Sheehan AE, Watts RJ, Freeman MR (2006) The Drosophila cell corpse engulfment receptor Draper mediates glial clearance of severed axons. Neuron 50:869-881

Mack TG, Reiner M, Beirowski B, Mi W, Emanuelli M, Wagner D, Thomson D, Gillingwater T, Court F, Conforti L, Fernando FS, Tarlton A, Andressen C, Addicks K, Magni G, Ribchester RR, Perry VH, Coleman MP (2001) Wallerian degeneration of injured axons and synapses is delayed by a Ube4b/Nmnat chimeric gene. Nat Neurosci 4:1199-1206

Macleod D, Dowman J, Hammond R, Leete T, Inoue K, Abeliovich A (2006) The familial Parkinsonism gene LRRK2 regulates neurite process morphology. Neuron 52:587-593

Mahad DJ, Ziabreva I, Campbell G, Lax N, White K, Hanson PS, Lassmann H, Turnbull DM (2009) Mitochondrial changes within axons in multiple sclerosis. Brain 132:1161-1174

Mandel RJ (1997) Midbrain injection of recombinant adeno-associated virus encoding rat glial cell line-derived neurotrophic factor protects nigral neurons in a progressive 6-hydroxydopamine-induced degeneration model of Parkinson's disease in rats. Proc Natl Acad Sci USA 94:14083-14088

McDonald CL, Bandtlow C, Reindl M (2011) Targeting the Nogo receptor complex in diseases of the central nervous system. Curr Med Chem 18:234-244

McIntosh TK, Smith DH, Meaney DF, Kotapka MJ, Gennarelli TA, Graham DI (1996) Neuropathological sequelae of traumatic brain injury: relationship to neurochemical and biomechanical mechanisms. Lab Invest 74:315-342

Meyer zu Horste G, Miesbach TA, Muller JI, Fledrich R, Stassart RM, Kieseier BC, Coleman MP, Sereda MW (2011) The Wlds transgene reduces axon loss in a Charcot-Marie-Tooth disease 1A rat model and nicotinamide delays post-traumatic axonal degeneration. Neurobiol Dis 42:1-8

Meythaler JM, Peduzzi JD, Eleftheriou E, Novack TA (2001) Current concepts: diffuse axonal injury-associated traumatic brain injury. Arch Phys Med Rehabil 82:1461-1471

Mi W, Beirowski B, Gillingwater TH, Adalbert R, Wagner D, Grumme D, Osaka H, Conforti L, Arnhold S, Addicks K, Wada K, Ribchester RR, Coleman MP (2005) The slow Wallerian degeneration gene, WldS, inhibits axonal spheroid pathology in gracile axonal dystrophy mice. Brain 128:405-416 
Miller BR, Press C, Daniels RW, Sasaki Y, Milbrandt J, DiAntonio A (2009) A dual leucine kinase-dependent axon self-destruction program promotes Wallerian degeneration. Nat Neurosci 12:387-389

Misgeld T (2011) Lost in elimination: mechanisms of axonal loss. e-Neuroforum 2:21-34

Misgeld T, Kerschensteiner M (2006) In vivo imaging of the diseased nervous system. Nat Rev Neurosci 7:449-463

Morfini G, Pigino G, Opalach K, Serulle Y, Moreira JE, Sugimori M, Llinás RR, Brady ST (2007) 1-Methyl-4-phenylpyridinium affects fast axonal transport by activation of caspase and protein kinase C. Proc Natl Acad Sci USA 104:2442-2447

Morfini GA, Burns M, Binder LI, Kanaan NM, LaPointe N, Bosco DA, Brown RH, Brown H, Tiwari A, Hayward L, Edgar J, Nave K-A, Garberrn J, Atagi Y, Song Y, Pigino G, Brady ST (2009) Axonal transport defects in neurodegenerative diseases. J Neurosci 29:12776-12786

Nath S, Goodwin J, Engelborghs Y, Pountney DL (2011) Raised calcium promotes $\alpha$-synuclein aggregate formation. Mol Cell Neurosci 46:516-526

Nicot A, Ratnakar PV, Ron Y, Chen C-C, Elkabes S (2003) Regulation of gene expression in experimental autoimmune encephalomyelitis indicates early neuronal dysfunction. Brain 126:398-412

Nihei K, McKee AC, Kowall NW (1993) Patterns of neuronal degeneration in the motor cortex of amyotrophic lateral sclerosis patients. Acta Neuropathol 86:55-64

Nikić I, Merkler D, Sorbara C, Brinkoetter M, Kreutzfeldt M, Bareyre FM, Brück W, Bishop D, Misgeld T, Kerschensteiner M (2011) A reversible form of axon damage in experimental autoimmune encephalomyelitis and multiple sclerosis. Nat Med 17:495-499

Nikolaeva MA, Mukherjee B, Stys PK (2005) $\mathrm{Na}^{+}$-dependent sources of intra-axonal $\mathrm{Ca}^{2+}$ release in rat optic nerve during in vitro chemical ischemia. J Neurosci 25:9960-9967

Oakley H, Cole SL, Logan S, Maus E, Shao P, Craft J, GuillozetBongaarts A, Ohno M, Disterhoft J, Van Eldik L, Berry R, Vassar R (2006) Intraneuronal beta-amyloid aggregates, neurodegeneration, and neuron loss in transgenic mice with five familial Alzheimer's disease mutations: potential factors in amyloid plaque formation. J Neurosci 26:10129-10140

Onorato M, Mulvihill P, Connolly J, Galloway P, Whitehouse P, Perry G (1989) Alteration of neuritic cytoarchitecture in Alzheimer disease. Prog Clin Biol Res 317:781-789

Orimo S, Uchihara T, Nakamura A, Mori F, Kakita A, Wakabayashi K, Takahashi H (2008) Axonal alpha-synuclein aggregates herald centripetal degeneration of cardiac sympathetic nerve in Parkinson's disease. Brain 131:642-50

Ouardouz M, Nikolaeva Ma, Coderre E, Zamponi GW, McRory JE, Trapp BD, Yin X, Wang W, Woulfe J, Stys PK (2003) Depolarization-induced $\mathrm{Ca}^{2+}$ release in ischemic spinal cord white matter involves L-type $\mathrm{Ca}^{2+}$ channel activation of ryanodine receptors. Neuron 40:53-63

Ozdinler PH, Benn S, Yamamoto TH, Güzel M, Brown RH, Macklis JD (2011) Corticospinal motor neurons and related subcerebral projection neurons undergo early and specific neurodegeneration in hSOD1G93A transgenic ALS mice. J Neurosci 31:4166-4177

Patterson KR, Ward SM, Combs B, Voss K, Kanaan NM, Morfini GA, Brady ST, Gamblin TC, Binder LI (2011) Heat shock protein 70 prevents both tau aggregation and the inhibitory effects of preexisting tau aggregates on fast axonal transport. Biochemistry 50:10300-10310

Pettigrew LC, Holtz ML, Craddock SD, Minger SL, Hall N, Geddes JW (1996) Microtubular proteolysis in focal cerebral ischemia. J Cereb Blood Flow Metab 16:1189-1202

Pettus EH, Povlishock JT (1996) Characterization of a distinct set of intraaxonal ultrastructural changes associated with traumatically induced alteration in axolemmal permeability. Brain Res 722:1-11
Pettus EH, Christman CW, Giebel ML, Povlishock JT (1994) Traumatically induced altered membrane permeability: its relationship to traumatically induced reactive axonal change. J Neurotrauma 11:507-522

Pigino G, Morfini G, Atagi Y, Deshpande A, Yu C, Jungbauer L, LaDu M, Busciglio J, Brady S (2009) Disruption of fast axonal transport is a pathogenic mechanism for intraneuronal amyloid beta. Proc Natl Acad Sci USA 106:5907-5912

Pineda AAM, Minohara M, Kawamura N, Matsushita T, Yamasaki R, Sun X, Piao H, Shimokawa H, J-ichi K (2011) Preventive and therapeutic effects of the selective Rho-kinase inhibitor fasudil on experimental autoimmune neuritis. J Neurol Sci 306:115-120

Plowey ED, Cherra SJ, Liu Y-J, Chu CT (2008) Role of autophagy in G2019S-LRRK2-associated neurite shortening in differentiated SH-SY5Y cells. J Neurochem 105:1048-1056

Podlisny MB, Stephenson DT, Frosch MP, Tolan DR, Lieberburg I, Clemens JA, Selkoe DJ (1993) Microinjection of synthetic amyloid beta-protein in monkey cerebral cortex fails to produce acute neurotoxicity. Am J Pathol 142:17-24

Probst A, Herzig MC, Mistl C, Ipsen S, Tolnay M (2001) Perisomatic granules (non-plaque dystrophic dendrites) of hippocampal CA1 neurons in Alzheimer's disease and Pick's disease: a lesion distinct from granulovacuolar degeneration. Acta Neuropathol 102:636-644

Przedborski S (2004) Molecular targets for neuroprotection. Amyotroph Lateral Scler Other Motor Neuron Disord 5 Suppl 1:14-18

Pun S, Santos AF, Saxena S, Xu L, Caroni P (2006) Selective vulnerability and pruning of phasic motoneuron axons in motoneuron disease alleviated by CNTF. Nat Neurosci 9:408-419

Raff MC, Whitmore AV, Finn JT (2002) Axonal self-destruction and neurodegeneration. Science 296:868-871

Rao MV, Nixon RA (2003) Defective neurofilament transport in mouse models of amyotrophic lateral sclerosis: a review. Neurochem Res 28:1041-1047

Ravikumar B, Vacher C, Berger Z, Davies JE, Luo S, Oroz LG, Scaravilli F, Easton DF, Duden R, O'Kane CJ, Rubinsztein DC (2004) Inhibition of mTOR induces autophagy and reduces toxicity of polyglutamine expansions in fly and mouse models of Huntington disease. Nat Genet 36:585-595

Ravikumar B, Acevedo-Arozena A, Imarisio S, Berger Z, Vacher C, O'Kane CJ, Brown SDM, Rubinsztein DC (2005) Dynein mutations impair autophagic clearance of aggregate-prone proteins. Nat Genet 37:771-776

Reitmeir R, Kilic E, Kilic U, Bacigaluppi M, ElAli A, Salani G, Pluchino S, Gassmann M, Hermann DM (2011) Post-acute delivery of erythropoietin induces stroke recovery by promoting perilesional tissue remodelling and contralesional pyramidal tract plasticity. Brain 134:84-99

Reyes NA, Fisher JK, Austgen K, VandenBerg S, Huang EJ, Oakes SA (2010) Blocking the mitochondrial apoptotic pathway preserves motor neuron viability and function in a mouse model of amyotrophic lateral sclerosis. J Clin Invest 120:3673-3679

Ries V, Silva RM, Oo TF, Cheng H-C, Rzhetskaya M, Kholodilov N, Flavell RA, Kuan C-Y, Rakic P, Burke RE (2008) JNK2 and JNK3 combined are essential for apoptosis in dopamine neurons of the substantia nigra, but are not required for axon degeneration. J Neurochem 107:1578-1588

Ritz B, Rhodes SL, Qian L, Schernhammer E, Olsen JH, Friis S (2010) L-type calcium channel blockers and Parkinson disease in Denmark. Ann Neurol 67:600-606

Rowland LP, Shneider NA (2001) Amyotrophic lateral sclerosis. N Eng J Med 344:1688-1700

Rowland JW, Hawryluk GWJ, Kwon B, Fehlings MG (2008) Current status of acute spinal cord injury pathophysiology and emerging therapies: promise on the horizon. Neurosurg Focus 25:E2 
Saatman KE, Creed J, Raghupathi R (2010) Calpain as a therapeutic target in traumatic brain injury. Neurotherapeutics 7:31-42

Sadasivan S, Dunn WA, Hayes RL, Wang KKW (2008) Changes in autophagy proteins in a rat model of controlled cortical impact induced brain injury. Biochem Biophys Res Commun 373:478-481

Sagot Y, Dubois-Dauphin M, Tan SA, de Bilbao F, Aebischer P, Martinou JC, Kato AC (1995) Bcl-2 overexpression prevents motoneuron cell body loss but not axonal degeneration in a mouse model of a neurodegenerative disease. J Neurosci 15:7727-7733

Saha AR, Hill J, Utton MA, Asuni AA, Ackerley S, Grierson AJ, Miller CC, Davies AM, Buchman VL, Anderton BH, Hanger DP (2004) Parkinson's disease alpha-synuclein mutations exhibit defective axonal transport in cultured neurons. J Cell Sci 117:1017-1024

Sasaki Y, Vohra BPS, Baloh RH, Milbrandt J (2009a) Transgenic mice expressing the Nmnat1 protein manifest robust delay in axonal degeneration in vivo. J Neurosci 29:6526-6534

Sasaki Y, Vohra BPS, Lund FE, Milbrandt J (2009b) Nicotinamide mononucleotide adenylyl transferase-mediated axonal protection requires enzymatic activity but not increased levels of neuronal nicotinamide adenine dinucleotide. J Neurosci 29:5525-5535

Satake W, Nakabayashi Y, Mizuta I, Hirota Y, Ito C, Kubo M, Kawaguchi T, Tsunoda T, Watanabe M, Takeda A, Tomiyama H, Nakashima K, Hasegawa K, Obata F, Yoshikawa T, Kawakami H, Sakoda S, Yamamoto M, Hattori N, Murata M, Nakamura Y, Toda T (2009) Genome-wide association study identifies common variants at four loci as genetic risk factors for Parkinson's disease. Nat Genet 41:1303-1307

Seidel K, Dunnen den WFA, Schultz C, Paulson H, Frank S, Vos RA de, Brunt ER, Deller T, Kampinga HH, Rüb U (2010a) Axonal inclusions in spinocerebellar ataxia type 3. Acta Neuropathol 120:449-460

Seidel K, Schöls L, Nuber S, Petrasch-Parwez E, Gierga K, Wszolek Z, Dickson D, Gai WP, Bornemann A, Riess O, Rami A, Dunnen WFA den, Deller T, Rüb U, Krüger R (2010b) First appraisal of brain pathology owing to A30P mutant alpha-synuclein. Ann Neurol 67:684-689

Sendtner M, Kreutzberg GW, Thoenen H (1990) Ciliary neurotrophic factor prevents the degeneration of motor neurons after axotomy. Nature 345:440-441

Shi R, Borgens RB (2000) Anatomical repair of nerve membranes in crushed mammalian spinal cord with polyethylene glycol. J Neurocytol 29:633-643

Shi P, Gal J, Kwinter DM, Liu X, Zhu H (2010) Mitochondrial dysfunction in amyotrophic lateral sclerosis. Biochim Biophys Acta 1802:45-51

Shirendeb UP, Calkins M, Manczak M, Anekonda V, Dufour B, McBride JL, Mao P, Reddy PH (2011) Mutant huntingtin's interaction with mitochondrial protein Drp1 impairs mitochondrial biogenesis and causes defective axonal transport and synaptic degeneration in Huntington's disease. Hum Mol Genet 21:406-420

Siebert H, Kahle PJ, Kramer ML, Isik T, Schlüter OM, SchulzSchaeffer WJ, Brück W (2010) Over-expression of alphasynuclein in the nervous system enhances axonal degeneration after peripheral nerve lesion in a transgenic mouse strain. J Neurochem 114:1007-1018

Sievers C, Platt N, Perry VH, Coleman MP, Conforti L (2003) Neurites undergoing Wallerian degeneration show an apoptotic-like process with annexin $\mathrm{V}$ positive staining and loss of mitochondrial membrane potential. Neurosci Res 46:161-169

Simons JP, Al-Shawi R, Minogue S, Waugh MG, Wiedemann C, Evangelou S, Loesch A, Sihra TS, King R, Warner TT, Hsuan JJ (2009) Loss of phosphatidylinositol 4-kinase 2alpha activity causes late onset degeneration of spinal cord axons. Proc Natl Acad Sci USA 106:11535-11539
Simón-Sánchez J, Schulte C, Bras JM, Sharma M, Gibbs JR, Berg D et al (2009) Genome-wide association study reveals genetic risk underlying Parkinson's disease. Nat Genet 41:1308-1312

Smith KDB, Kallhoff V, Zheng H, Pautler RG (2007) In vivo axonal transport rates decrease in a mouse model of Alzheimer's disease. Neuroimage 35:1401-1408

Snow AD, Sekiguchi R, Nochlin D, Fraser P, Kimata K, Mizutani A, Arai M, Schreier WA, Morgan DG (1994) An important role of heparan sulfate proteoglycan (Perlecan) in a model system for the deposition and persistence of fibrillar A beta-amyloid in rat brain. Neuron 12:219-234

Sobue G, Sahashi K, Takahashi A, Matsuoka Y, Muroga T, Sobue I (1983) Degenerating compartment and functioning compartment of motor neurons in ALS: possible process of motor neuron loss. Neurology 33:654-657

Song M-S, Saavedra L, Chaves EIP de (2006) Apoptosis is secondary to non-apoptotic axonal degeneration in neurons exposed to Abeta in distal axons. Neurobiol Aging 27:1224-1238

Staal JA, Dickson TC, Gasperini R, Liu Y, Foa L, Vickers JC (2010) Initial calcium release from intracellular stores followed by calcium dysregulation is linked to secondary axotomy following transient axonal stretch injury. J Neurochem 112:1147-1155

Stagi M, Gorlovoy P, Larionov S, Takahashi K, Neumann H (2006) Unloading kinesin transported cargoes from the tubulin track via the inflammatory c-Jun N-terminal kinase pathway. FASEB J 20:2573-2575

Stamer K, Vogel R, Thies E, Mandelkow E, Mandelkow E-M (2002) Tau blocks traffic of organelles, neurofilaments, and APP vesicles in neurons and enhances oxidative stress. J Cell Biol 156:10511063

Stirling DP, Stys PK (2010) Mechanisms of axonal injury: internodal nanocomplexes and calcium deregulation. Trends Mol Med 16:160-170

Stokin GB, Lillo C, Falzone TL, Brusch RG, Rockenstein E, Mount SL, Raman R, Davies P, Masliah E, Williams DS, Goldstein LSB (2005) Axonopathy and transport deficits early in the pathogenesis of Alzheimer's disease. Science 307:1282-1288

Stys PK, Waxman SG, Ransom BR (1992) Ionic mechanisms of anoxic injury in mammalian CNS white matter: role of $\mathrm{Na}^{+}$channels and $\mathrm{Na}^{+}-\mathrm{Ca}^{2+}$ exchanger. J Neurosci 12:430-439

Sun X, Minohara M, Kikuchi H, Ishizu T, Tanaka M, Piao H, Osoegawa M, Ohyagi Y, Shimokawa H, Kira J-I (2006) The selective Rho-kinase inhibitor Fasudil is protective and therapeutic in experimental autoimmune encephalomyelitis. J Neuroimmunol 180:126-134

Tamsett TJ, Picchione KE, Bhattacharjee A (2009) NAD+activates $\mathrm{KNa}$ channels in dorsal root ganglion neurons. J Neurosci 29:5127-5134

Tang-Schomer MD, Patel AR, Baas PW, Smith DH (2010) Mechanical breaking of microtubules in axons during dynamic stretch injury underlies delayed elasticity, microtubule disassembly, and axon degeneration. FASEB J 24:1401-1410

Tesseur I, Van Dorpe J, Bruynseels K, Bronfman F, Sciot R, Van Lommel A, Van Leuven F (2000) Prominent axonopathy and disruption of axonal transport in transgenic mice expressing human apolipoprotein E4 in neurons of brain and spinal cord. Am J Pathol 157:1495-1510

Tönges L, Koch J, Bähr M, Lingor P (2011) ROCKing regenerationRho kinase inhibition as molecular target for neurorestoration. Front Mol Neurosci 4:39

Touma E, Kato S, Fukui K, Koike T (2007) Calpain-mediated cleavage of collapsin response mediator protein (CRMP)-2 during neurite degeneration in mice. Eur J Neurosci 26:3368-3381

Trapp B, Peterson J, Ransohoff R, Rudick R, Mörk S, Bö L (1998) Axonal transection in the lesions of multiple sclerosis. N Eng J Med 338:278-285 
Tsai J, Grutzendler J, Duff K, Gan W-B (2004) Fibrillar amyloid deposition leads to local synaptic abnormalities and breakage of neuronal branches. Nat Neurosci 7:1181-1183

Utton MA, Noble WJ, Hill JE, Anderton BH, Hanger DP (2005) Molecular motors implicated in the axonal transport of tau and alpha-synuclein. J Cell Sci 118:4645-4654

Van Damme P, Dewil M, Robberecht W, Van Den Bosch L (2005) Excitotoxicity and amyotrophic lateral sclerosis. Neurodegener Dis 2:147-159

Vavlitou N, Sargiannidou I, Markoullis K, Kyriacou K, Scherer SS, Kleopa KA (2010) Axonal pathology precedes demyelination in a mouse model of X-linked demyelinating/type I Charcot-Marie Tooth neuropathy. J Neuropathol Exp Neurol 69:945-958

Veeranna A, Kaji T, Boland B, Odrljin T, Mohan P, Basavarajappa BS, Peterhoff C, Cataldo A, Rudnicki A, Amin N, Li BS, Pant HC, Hungund BL, Arancio O, Nixon RA (2004) Calpain mediates calcium-induced activation of the erk1,2 MAPK pathway and cytoskeletal phosphorylation in neurons: relevance to Alzheimer's disease. Am J Pathol 165:795-805

Vershinin M, Carter BC, Razafsky DS, King SJ, Gross SP (2007) Multiple-motor based transport and its regulation by Tau. Proc Natl Acad Sci USA 104:87-92

Vosler PS, Brennan CS, Chen J (2008) Calpain-mediated signaling mechanisms in neuronal injury and neurodegeneration. Mol Neurobiol 38:78-100

Waetzig V, Herdegen T (2005) Context-specific inhibition of JNKs: overcoming the dilemma of protection and damage. Trends Pharmacol Sci 26:455-461

Waller A (1850) Experiments on the section of glossopharyngeal and hypoglossal nerves of the frog and observations of the alternatives produced thereby in the structure of their primitive fibres. Philos Trans R Soc Lond Biol 140:423-429

Wang D, Ayers MM, Catmull DV, Hazelwood LJ, Bernard CCA, Orian JM (2005) Astrocyte-associated axonal damage in pre-onset stages of experimental autoimmune encephalomyelitis. Glia 51:235-240

Wang J, Zhai Q, Chen Y, Lin E, Gu W, McBurney MW, He Z (2005) A local mechanism mediates NAD-dependent protection of axon degeneration. J Cell Biol 170:349-355

Wang QJ, Ding Y, Kohtz DS, Mizushima N, Cristea IM, Rout MP, Chait BT, Zhong Y, Heintz N, Yue Z (2006) Induction of autophagy in axonal dystrophy and degeneration. J Neurosci 26:8057-8068

Weibel D, Kreutzberg GW, Schwab ME (1995) Brain-derived neurotrophic factor (BDNF) prevents lesion-induced axonal die-back in young rat optic nerve. Brain Res 679:249-254

Weishaupt N, Silasi G, Colbourne F, Fouad K (2010) Secondary damage in the spinal cord after motor cortex injury in rats. $\mathrm{J}$ Neurotrauma 27:1387-1397

Wen Y, Parrish JZ, He R, Zhai RG, Kim MD (2011) Nmnat exerts neuroprotective effects in dendrites and axons. Mol Cell Neurosci 48:1-8

Weston CR, Davis RJ (2007) The JNK signal transduction pathway. Curr Opin Cell Biol 19:142-149

Westphal V, Rizzoli SO, Lauterbach MA, Kamin D, Jahn R, Hell SW (2008) Video-rate far-field optical nanoscopy dissects synaptic vesicle movement. Science 320:246-249
Whitmore AV, Lindsten T, Raff MC, Thompson CB (2003) The proapoptotic proteins Bax and Bak are not involved in Wallerian degeneration. Cell Death Differ 10:260-261

Wilbrey AL, Haley JE, Wishart TM, Conforti L, Morreale G, Beirowski B, Babetto E, Adalbert R, Gillingwater TH, Smith T, Wyllie DJA, Ribchester RR, Coleman MP (2008) VCP binding influences intracellular distribution of the slow Wallerian degeneration protein, Wld (S). Mol Cell Neurosci 38:325-340

Willesen MG, Gammeltoft S, Vaudano E (2002) Activation of the c-Jun $\mathrm{N}$ terminal kinase pathway in an animal model of Parkinson's disease. Ann N Y Acad Sci 973:237-240

Wirths O, Weis J, Kayed R, Saido TC, Bayer TA (2007) Agedependent axonal degeneration in an Alzheimer mouse model. Neurobiol Aging 28:1689-1699

Wong ASL, Lee RHK, Cheung AY, Yeung PK, Chung SK, Cheung ZH, Ip NY (2011) Cdk5-mediated phosphorylation of endophilin B1 is required for induced autophagy in models of Parkinson's disease. Nat Cell Biol 13:568-579

Xue Y-Q, Ma B-F, Zhao L-R, Tatom JB, Li B, Jiang L-X, Klein RL, Duan W-M (2010) AAV9-mediated erythropoietin gene delivery into the brain protects nigral dopaminergic neurons in a rat model of Parkinson's disease. Gene Ther 17:83-94

Yahata N, Yuasa S, Araki T (2009) Nicotinamide mononucleotide adenylyltransferase expression in mitochondrial matrix delays Wallerian degeneration. J Neurosci 29:6276-6284

Yan T, Feng Y, Zheng J, Ge X, Zhang Y, Wu D, Zhao J, Zhai Q (2010) Nmnat2 delays axon degeneration in superior cervical ganglia dependent on its NAD synthesis activity. Neurochem Int 56:101-106

Yang Y, Fukui K, Koike T, Zheng X (2007) Induction of autophagy in neurite degeneration of mouse superior cervical ganglion neurons. Eur J Neurosci 26:2979-2988

Yankner BA, Duffy LK, Kirschner DA (1990) Neurotrophic and neurotoxic effects of amyloid beta protein: reversal by tachykinin neuropeptides. Science 250:279-282

Yoshimura K, Ueno M, Lee S, Nakamura Y, Sato A, Yoshimura K, Kishima H, Yoshimine T, Yamashimta T (2011) C-Jun N-terminal kinase induces axonal degeneration and limits motor recovery after spinal cord injury in mice. Neurosci Res 71:266-277

Yue Z (2007) Regulation of neuronal autophagy in axon: implication of autophagy in axonal function and dysfunction/degeneration. Autophagy 3:139-141

Zhai Q, Wang J, Kim A, Liu Q, Watts R, Hoopfer E, Mitchison T, Luo $\mathrm{L}, \mathrm{He} Z \mathrm{Z}$ (2003) Involvement of the ubiquitin-proteasome system in the early stages of Wallerian degeneration. Neuron 39:217-225

Zhao C, Takita J, Tanaka Y, Setou M, Nakagawa T, Takeda S, Yang HW, Terada S, Nakata T, Takei Y, Saito M, Tsuji S, Hayashi Y, Hirokawa N (2001) Charcot-Marie-Tooth disease type 2A caused by mutation in a microtubule motor KIF1Bbeta. Cell 105:587-597

Zhu Y-B, Sheng Z-H (2011) Increased axonal mitochondrial mobility does not slow amyotrophic lateral sclerosis (ALS)-like disease in mutant SOD1 mice. J Biol Chem 286:23432-23440

Ziv NE, Spira ME (1995) Axotomy induces a transient and localized elevation of the free intracellular calcium concentration to the millimolar range. J Neurophysiol 74:2625-2637 